\title{
Practical Recommendations of the Obesity Management Task Force of the European Association for the Study of Obesity for the Post-Bariatric Surgery Medical Management
}

\author{
Luca Busetto $^{a} \quad$ Dror Dicker $^{b} \quad$ Carmil Azran $^{c}$ Rachel L. Batterham ${ }^{d, e, f}$ \\ Nathalie Farpour-Lambert ${ }^{g} \quad$ Martin Fried $^{h} \quad$ Jøran Hjelmesæth ${ }^{i} \quad$ Johann Kinz $^{j}$

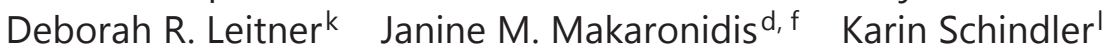 \\ Hermann Toplak ${ }^{k}$ Volkan Yumuk ${ }^{m}$ \\ ${ }^{a}$ Department of Internal Medicine, University of Padova, Padova, Italy; ${ }^{b}$ Department of Internal \\ Medicine D and Obesity Clinic, Hasharon Hospital, Rabin Medical Center, Petah Tikva, Sackler \\ School of Medicine Tel Aviv University, Tel Aviv, Israel; ' ${ }^{C}$ Clinical Pharmacy, Herzliya Medical Center, \\ Herzliya, Israel; ${ }^{d}$ Centre for Obesity Research, Rayne Institute, Department of Medicine, University \\ College London, London, UK; e University College London Hospital Bariatric Centre for Weight \\ Management and Metabolic Surgery, University College London Hospital, London, UK; ${ }^{f}$ National \\ Institute of Health Research, University College London Hospital Biomedical Research Centre, \\ London, UK; ${ }^{9}$ Obesity Prevention and Care Program Contrepoids, Service of Therapeutic Education \\ for Chronic Diseases, Department of Community Medicine, Primary Care and Emergency, \\ University Hospitals of Geneva and University of Geneva, Geneva, Switzerland; h OB Klinika, Centre \\ for Treatment of Obesity and Metabolic Disorders, 1st Faculty of Medicine, Charles University, \\ Prague, Czech Republic; 'Morbid Obesity Centre, Vestfold Hospital Trust and Department \\ of Endocrinology, Morbid Obesity and Preventive Medicine, Institute of Clinical Medicine, \\ University of Oslo, Oslo, Norway; ${ }^{j}$ Department of Psychiatry and Psychotherapy II, Medical

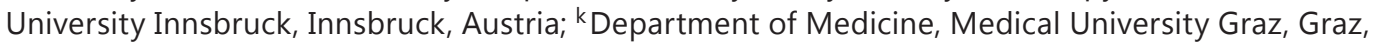 \\ Austria; 'Department of Medicine III, Medical University of Vienna, Vienna, Austria; ${ }^{m}$ Division of \\ Endocrinology, Metabolism and Diabetes, Department of Medicine, Istanbul University Cerrahpasa \\ Medical Faculty, Istanbul, Turkey
}

\section{Keywords}

European guidelines - Obesity management - Bariatric surgery - Nutrition - Diabetes mellitus . Sleep apnoea · Hypertension · Pregnancy · Psychological aspects · Weight maintenance

\begin{abstract}
Bariatric surgery is today the most effective long-term therapy for the management of patients with severe obesity, and its use is recommended by the relevant guidelines of the management of obesity in adults. Bariatric surgery is in general safe and effective, but it can cause new clinical problems and is associated with specific diagnostic, preventive and therapeutic needs. For clinicians, the acquisition of special knowledge and skills is required in order to deliver appropriate and effective care to the post-bariatric patient. In the present recommen- 
Busetto et al.: Practical Recommendations of the Obesity Management Task Force of the European Association for the Study of Obesity for the Post-Bariatric Surgery Medical Management

dations, the basic notions needed to provide first-level adequate medical care to post-bariatric patients are summarised. Basic information about nutrition, management of co-morbidities, pregnancy, psychological issues as well as weight regain prevention and management is derived from current evidences and existing guidelines. A short list of clinical practical recommendations is included for each item. It remains clear that referral to a bariatric multidisciplinary centre, preferably the one performing the original procedure, should be considered in case of more complex clinical situations.

(c) 2017 The Author(s)

Published by S. Karger GmbH, Freiburg

\section{Introduction}

Bariatric surgery produces sustained long-term weight loss and reduces co-morbidity burden and mortality in patients with severe obesity [1]. Current obesity guidelines recommend bariatric surgery according to BMI levels and associated obesity-related diseases [2]. Therefore, the total number of bariatric procedures performed world-wide has increased steadily in recent years [3].

On the other hand, bariatric patients may face new specific multifaceted clinical problems after surgery. Eating habits need to adapt to the new gastro-intestinal physiology, and nutritional deficits may arise according to the type of bariatric procedure. Management of obesityassociated disease needs to be modulated according to weight loss taking into account the possibility of changes in drug pharmacokinetics. Specific problems may arise in women during pregnancy, and the patients may experience some psychological difficulties in adapting to the profound changes in eating behaviour and body image. Finally, weight regain can occur and should be prevented and managed.

Multidisciplinary long-term follow-up is recommended after bariatric surgery, and the provision of an adequate follow-up programme is mandatory for bariatric centres [2]. However, giving the accumulating numbers of bariatric patients, follow-up should be at least in part transferred to primary care over time. Moreover, post-bariatric patients may confront obesity specialists, dieticians and nurses not specifically trained in bariatric medicine with thus far unknown problems in their professional activity. Referral to the bariatric centre is often necessary and should be possible, but there is a growing need for dissemination of firstlevel knowledge in managing bariatric patients. The aim of this document is therefore to provide a brief but comprehensive review of the major clinical points in bariatric medicine and some practical recommendations for post-bariatric surgery medical management. It remains clear that referral to a bariatric multidisciplinary centre, preferably the one performing the original procedure, should be considered in case of more complex clinical situations.

In this document, we tried therefore to convey the basic skills to those health care professionals that need to provide adequate first-level medical care to post-bariatric patients. Firstlevel information about nutritional management, micronutrients supplementation, management of co-morbidities, pharmacotherapy after bariatric surgery, pregnancy after bariatric surgery, psychological aspects as well as weight regain prevention and management are derived from current evidences and existing guidelines. A short list of clinical practical recommendations is derived from the full paper and included in each session. The levels of evidence and grades of these recommendations were also reported. The grading system was the same used in previous guidelines released by the European Association for the Study of Obesity (EASO) [2] (table 1). 
Busetto et al.: Practical Recommendations of the Obesity Management Task Force of the European Association for the Study of Obesity for the Post-Bariatric Surgery Medical Management

Table 1. Levels of evidence, grades of recommendation and good practice points [2]

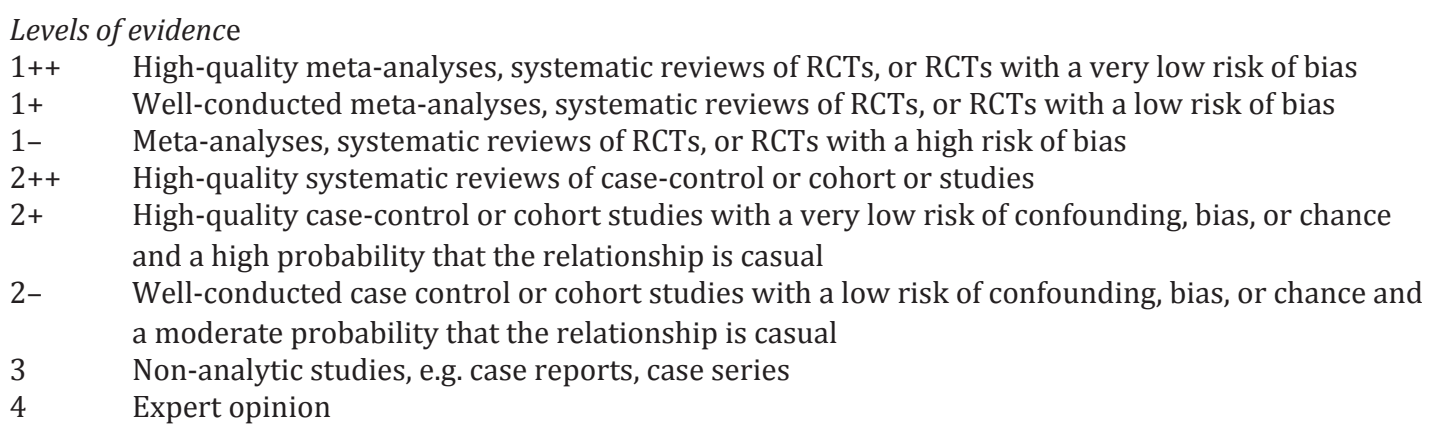

Grades of recommendation

A At least one meta-analysis, systematic review, or RCT rated as 1++, and directly applicable to the target population; or a systematic review of RCTs or a body of evidence consisting principally of studies rated as 1+, directly applicable to the target population, and demonstrating overall consistency of results

B A body of evidence including studies rated as $2++$, directly applicable to the target population, and demonstrating overall consistency of results; or extrapolated evidence from studies rated as $1++$, or $1+$

C A body of evidence including studies rated as $2+$, directly applicable to the target population, and demonstrating overall consistency of results; or extrapolated evidence from studies rated as $2++$

$\mathrm{D}$ Evidence level 3 or 4; or extrapolated evidence from studies rated as 2+

Good practice points

RBP Recommended best practice based on the clinical experience of the guideline development group

\section{Nutritional Management}

Bariatric procedures induce significant and long-lasting changes in nutritional habits and eating behaviour. The anatomical and functional modifications of the gastro-intestinal tract produced by bariatric surgery always require the adaptation of patients' eating behaviour to the new gastro-intestinal physiology, and procedure-specific nutritional problems and symptoms may occur. The nutritional management of the post-bariatric patients requires therefore specific nutritional skills and the intervention of experienced nutritionists and dieticians. Detailed guidelines for post-operative bariatric nutritional management have been published [4, 5] and recently updated [6]. In this section, first-level information about early, late and life-long nutritional management, protein intake and supplementation as well as specific nutritional problems is included. A short list of graded clinical practical recommendations on nutritional management is reported in table 2 .

\section{Early, Late and Life-Long Nutritional Management}

Most bariatric procedures include the reduction of the volume of the stomach and/or the creation of a small gastric pouch. Therefore, the ingestion of solid foods in the first days after surgery is impossible and a gradual change of food consistency in the first post-operative weeks is preferred in order to avoid or minimise regurgitation and vomiting, which can threaten the integrity and safety of the recent surgical procedure, and result in severe vitamin B1 (thiamine) deficiency [5]. A low-sugar clear liquid meal programme is usually initiated within $24 \mathrm{~h}$ of surgery, and patients are then instructed to gradually and progressively change the food consistency, moving from clear liquids to soft or creamy foods and then to solid 
Busetto et al.: Practical Recommendations of the Obesity Management Task Force of the European Association for the Study of Obesity for the Post-Bariatric Surgery

Medical Management

Table 2. List of graded clinical practical recommendations for post-bariatric nutritional management

\begin{tabular}{lll}
\hline Recommendations & $\begin{array}{l}\text { Level of } \\
\text { evidence }\end{array}$ & $\begin{array}{l}\text { Grade of } \\
\text { recommendation* }\end{array}$ \\
\hline $\begin{array}{l}\text { Bariatric patients should receive periodic counselling by a registered } \\
\text { dietician about long-term dietary modifications. The focus of dietary } \\
\text { counselling should be the adaptation of patients eating behaviour to the } \\
\text { surgical procedure and the general qualitative aspects of a healthy } \\
\text { nutrient-dense diet. }\end{array}$ & $\mathrm{A}$ \\
\hline
\end{tabular}

Regular physical activity should be encouraged after bariatric surgery, 1

A starting since after the recovery from surgery. Patients should be advised to incorporate moderate aerobic physical activity to include a minimum of $150 \mathrm{~min} /$ week and goal of $300 \mathrm{~min} /$ week, including strength training 2-3 times per week.

Nutritional counselling should address the problem of protein intake, particularly in the first months after surgery. A minimal protein intake of $60 \mathrm{~g} /$ day and up to $1.5 \mathrm{~g} / \mathrm{kg}$ ideal body weight per day should be targeted. The use of liquid protein supplements ( $30 \mathrm{~g} /$ day) can facilitate adequate protein intake in the first period after surgery.

Nutritional manipulation should be the first line treatment for the 1 A control of dumping syndrome. Medical therapy with octreotide should be considered in patients who fail to be controlled with dietary modifications.

*For the grading system refers to table 1.

chewable items over a period of 2-4 weeks [4-6]. Patients should be trained to chew adequately and receive clear instruction about post-operative meal initiation and progression by an experienced bariatric dietician before discharge [6]. There are protocols for meal progression specific to most of the bariatric procedures [4], but bariatric centres may design their own protocols taking into account personal and regional variations in food preferences.

After the end of the post-operative diet and thereafter, patients should receive periodic counselling by a registered dietician about long-term dietary modifications in order to maximize the results of the bariatric procedure and reduce the risk of late weight regain. Patients who received regular dietary counselling for the first 4 months after surgery achieved a slightly greater weight loss than patients who received standard post-operative care not involving counselling in a randomised trial, although the difference did not reach statistical significance [7]. Patients in the dietary counselling arm did report significant changes in several eating behaviours believed to be important for successful long-term weight maintenance [7]. The focus of dietary counselling should be the adaptation of patients' eating behaviour to the surgical procedure and the general qualitative aspects of a healthy nutrientdense diet. In particular, patients with gastric restriction should be counselled to eat three small meals during the day and chew small bites of food thoroughly before swallowing, without drinking beverages at the same time (more than $30 \mathrm{~min}$ apart) [4-6].

A positive relationship between physical activity levels and the amount of weight loss after bariatric surgery has been observed in several studies [8], and regular physical activity is considered a critical factor for weight maintenance. Regular physical activity should therefore be encouraged after bariatric surgery, starting immediately after the recovery from 
Busetto et al.: Practical Recommendations of the Obesity Management Task Force of the European Association for the Study of Obesity for the Post-Bariatric Surgery

Medical Management

surgery. Patients should be advised to incorporate moderate aerobic physical activity, i.e., a minimum of $150 \mathrm{~min} /$ week (with a goal of $300 \mathrm{~min} /$ week) as well as strength training 2-3 times/week [6].

\section{Protein Intake and Protein Supplementation}

Sufficient protein intake is considered protective against the loss of lean body mass in any situation when a rapid weight loss occurs. However, protein intake is generally reduced following bariatric surgery [9]. A preference toward low-protein foods is common after all procedures having a restrictive component, particularly in the first months after surgery which is based on gastric intolerance to protein-rich foods [4]. Usually, most food intolerances tend to diminish over time, and protein intake tends to increase, but protein intake may be lower than recommended in the first year after surgery, when most part of weight loss occurs. Therefore, dietary counselling should address the problem of protein intake, particularly in the first months after surgery. Current guidelines suggest a minimal protein intake of $60 \mathrm{~g} /$ day and up to $1.5 \mathrm{~g} / \mathrm{kg}$ ideal body weight per day, but higher amounts of protein intake (up to $2.1 \mathrm{~g} / \mathrm{kg}$ ideal body weight per day) may be required in individual cases [6]. The use of liquid protein supplements $(30 \mathrm{~g} /$ day $)$ can facilitate adequate protein intake in the first period after surgery.

Bariatric procedures involving a certain degree of malabsorption can cause protein malnutrition. The incidence of protein malnutrition depends on the degree of the malabsorption as well as on the dietary habits and the protein requirements of the patients. A 13\% incidence has been reported after distal Roux-en Y gastric bypass (RYGB) with a Roux limb $\geq$ $150 \mathrm{~cm}$ [10], but a much lower rate $(<5 \%)$ has been reported after RYGB with a Roux limb $<$ $150 \mathrm{~cm}$ [11]. An incidence of protein malnutrition ranging from 3 to $18 \%$ has been reported after biliopancreatic diversion [4]. The occurrence of any pathologic (infections) or physiologic (pregnancy) state characterised by an increase of protein requirements may precipitate protein malnutrition in individual patients. Prevention of protein malnutrition involves regular assessment of protein intake, encouraging the ingestion of protein-rich foods $(>60$ $\mathrm{g} /$ day) divided into several meals and the use of modular protein supplements [4]. Parenteral nutrition is mandatory in case of severe non-responsive protein malnutrition, and surgical revision with lengthening of the common channel to decrease malabsorption should be considered if a patient remains dependent on parenteral nutrition or has recurrent episodes of protein depletion [12].

\section{Specific Nutritional Problems}

Food Intolerance, Vomiting and Regurgitation: Food intolerances are common after any bariatric procedure involving a functional or anatomical reduction of the gastric volume. The foods most frequently involved are meat products, bread, rice and pasta. Failure of the patient to cope with the changes in eating behaviour requested by gastric restriction (rapid eating, insufficient chewing or drinking during meals) is frequently involved in causing food intolerances. Food intolerances tend to diminish over time, but patients may remain intolerant to particular foods even in the long term. Educational support from an experienced dietician may help patients to acquire a better behavioural adaptation and/or to use alternative foods [7]. Food intolerances and behavioural errors may cause episodes of vomiting or food regurgitation during meals, frequently described by the patients as 'spitting up' or 'food getting stuck' [4]. Such episodes are usually self-limiting, may occur occasionally in the first months after surgery and should be considered normal in a patient still adapting to his new gastric anatomy [4]. However, in case of persistent ( $>6$ months) and/or frequent vomiting, a physical cause should be suspected and a surgical diagnostic work-up considered [4]. Persistent vomiting heavily disturbing normal eating and greatly reducing energy intake can precipitate 


\begin{tabular}{l|l}
\hline Obes Facts 2017;10:597-632 & \\
\hline DOI: 10.1159/000481825 & $\begin{array}{l}\text { @ } 2017 \text { The Author(s). Published by S. Karger GmbH, Freiburg } \\
\text { www.karger.com/ofa }\end{array}$ \\
\hline $\begin{array}{ll}\text { Busetto et al.: Practical Recommendations of the Obesity Management Task Force of } \\
\text { the European Association for the Study of Obesity for the Post-Bariatric Surgery }\end{array}$ \\
Medical Management & +5 \\
\hline Shock & +4 \\
Fainting, syncope, unconsciousness & +4 \\
Desire to lie or sit down & +3 \\
Breathlessness, dyspnoea & +3 \\
Weakness, exhaustion & +3 \\
Sleepiness, drowsiness, apathy, falling asleep & +3 \\
Palpitation & +2 \\
Restlessness & +2 \\
Dizziness & +1 \\
Headaches & +1 \\
Feeling of warmth, sweating, pallor, clammy skin & +1 \\
Nausea & +1 \\
Abdominal fullness, meteorism & +1 \\
Borborygmus & -1 \\
Eructation & -4 \\
Vomiting &
\end{tabular}

Table 3. Dumping symptoms according to the Sigstad's scoring system [14]

the onset of an acute state of thiamine deficiency that need to be considered and prevented (see below).

Diarrhoea and Steatorrhoea: Disordered bowel habits are frequent after malabsorptive bariatric surgery, and patients undergoing biliopancreatic diversion or duodenal switch frequently reported intestinal symptoms that may impair quality of life or interfere with social functioning (increased number of bowel movements with loose stools or diarrhoea, faecal urgency, abdominal bloating and smelling flatulence) [13]. These symptoms are related to fat and carbohydrate malabsorption and to bacterial overgrowth. Dietary manipulation, with the avoidance of fatty or starch-rich foods, and the regular or intermittent use of intestinal antibiotics (example: rifamixin 200-400 mg/bid for 7 days every month) may help.

Dumping Syndrome and Hypoglycaemia: Dumping refers to the post-prandial occurrence of a constellation of symptoms elicited by the rapid transit of calorie-dense food to the small bowel. The symptoms may be non-specific, but a correct diagnosis is facilitated by the application of the Sigstad's score, a diagnostic tool based on weighing factors assigned to symptoms of the syndrome: a score index higher than 7 points is suggestive of dumping (table 3) [14]. Dumping syndrome was believed to be typical of gastric bypass $(70-75 \%$ of patients in the first year after surgery) [4], but it has been described also after sleeve gastrectomy ( $40 \%$ of patients 6 months after surgery) [15]. Some authors suggested a possible role of dumping in determining weight loss after gastric bypass, through the negative conditioning for consuming energy-dense foods [16], but this role has been questioned [17]. Dumping was classically attributed to a rapid increase in the osmolality of the intestinal content, with influx of fluid into the intestinal lumen, intestinal distention, fluid sequestration, decreased intravascular volume and hypotension [18], but the changes in the secretion of gastro-intestinal hormones (GLP-1) described after bariatric surgery probably also play a role in the pathogenesis of the syndrome [19]. In clinical practice, symptoms of dumping syndrome can be classified as early or late, depending on how soon after food ingestion they occur: early symptoms occur about 10-30 min after meal, whereas late symptoms occur 1-3 h after food ingestion [20]. Late dumping is strictly related to the occurrence of reactive hypoglycaemia and may be more linked to changes in gastro-intestinal hormones and insulin secretion [21, 22]. Nutritional manipulation is usually sufficient to control dumping. Nutritional tips comprise eating small but frequent meals, avoiding ingestion of liquids within $30 \mathrm{~min}$ of a solid-food meal, avoiding simple sugars, increasing intake of fibre and complex carbohydrates and increasing protein intake [4]. Late symptoms and reactive hypoglycaemia may be also prevented by drinking 
Busetto et al.: Practical Recommendations of the Obesity Management Task Force of the European Association for the Study of Obesity for the Post-Bariatric Surgery

Medical Management

Table 4. List of graded clinical practical recommendations for post-bariatric micronutrients supplementation

Recommendations

Level of

evidence
Grade of recommendation*

Long-term mineral and multivitamin supplementation should be

3

D

prescribed to every bariatric patient according to the procedure.

Periodic laboratory surveillance for nutritional deficiencies is

recommended and supplementation should be individualized

accordingly, with patients with demonstrated micronutrient

deficiencies treated with the respective micronutrient.

Oral or parenteral thiamine supplementation should be promptly

started in every bariatric patient suffering from persistent vomiting

severe enough to interfere with regular nutrition, even in the absence

or before confirmatory laboratory data.

*For the grading system refers to table 1 .

half a glass of orange juice (or taking the equivalent small sugar supplement) about $1 \mathrm{~h}$ after eating [4]. Medical therapy has its role in patients who fail to be controlled with dietary modifications. Several drugs have been described as beneficial in symptom control, but without consistent success. The effectiveness of octreotide, at the initial recommended dose of 25-50 $\mu \mathrm{g}$ administered subcutaneously 2-3 times daily and 15-30 min before meals, in ameliorating symptoms of dumping is supported by several randomised trials [23], and this drug may be therefore helpful in some patients [4]. However, in case of severe hypoglycaemic events with neuroglycopenic symptoms, alternative causes of hyperinsulinaemic hypoglycaemia (pancreatic beta-cells hyperplasia, insulinoma) should be considered and specific diagnostic algorithms have been proposed [24].

\section{Micronutrient Supplementation}

The occurrence of vitamin and mineral deficiencies is one of the most common and compelling problems after bariatric surgery. Prevention, detection and treatment of these deficiencies represent cornerstones of long-term follow-up in post-bariatric patients. In this section, first-level information about general and procedure-specific nutritional deficits, recommended micronutrient supplementation and nutritional follow-up is included. A short list of graded clinical practical recommendations on micronutrient supplementation is given in table 4.

\section{General and Procedure-Specific Nutritional Deficits}

The anatomical characteristics and the mechanisms of action of the various procedures mostly dictate the frequency and severity of vitamin and mineral deficiencies after bariatric surgery (table 5). Nutritional deficiencies are uncommon after purely gastric restrictive procedures not altering intestinal continuity and normal digestive processes, but more common after surgical procedures inducing some degree of malabsorption [4]. However, the occurrence of nutritional deficits is also influenced by factors independent from the surgical technique, such as regular and nutrient-dense food intake and adherence with post-operative vitamin and mineral supplementation. Clinical, socio-economic and psychological factors 
Busetto et al.: Practical Recommendations of the Obesity Management Task Force of the European Association for the Study of Obesity for the Post-Bariatric Surgery

Medical Management

Table 5. Major vitamins and minerals deficiencies after bariatric surgery: clinical manifestations and estimated frequency according to the bariatric procedure

\begin{tabular}{lll}
\hline Deficiency & Key clinical manifestations & Procedure-related frequency \\
\hline Iron & microcytic anaemia & $\begin{array}{l}\text { AGB }+ \\
\text { SG }++ \\
\text { RYGB, BPD, BPD/DS +++ }\end{array}$ \\
\hline Vitamin B12 & $\begin{array}{l}\text { megaloblastic anaemia } \\
\text { neurologic abnormalities }\end{array}$ & SG, RYGB, BPD, BPD/DS ++ \\
\hline Vitamin D (and calcium) & $\begin{array}{l}\text { bone demineralization } \\
\text { increased risk of fractures }\end{array}$ & $\begin{array}{l}\text { RYGB ++ } \\
\text { BPD, BPD/DS +++ }\end{array}$ \\
\hline Vitamin A & $\begin{array}{l}\text { ocular xerosis } \\
\text { night blindness symptoms }\end{array}$ & \\
\hline Vitamin E & $\begin{array}{l}\text { anaemia } \\
\text { ophthalmoplegia }\end{array}$ & BPD, BPD/DS +++ ++ \\
\hline Vitamin K & peripheral neuropathy & \\
\hline
\end{tabular}

$\mathrm{AGB}=$ Adjustable gastric banding; $\mathrm{SG}=$ sleeve gastrectomy; RYGB = gastric bypass; $\mathrm{BPD}=$ biliopancreatic diversion; BPD/DS = biliopancreatic diversion with duodenal switch.

may therefore play a role [5]. Detailed descriptions of vitamin and mineral deficiencies that may be encountered after bariatric surgery, their symptoms and consequences, and the rationale for vitamin supplementation have already been published [4-6, 25].

Iron: Iron deficiency with or without anaemia is common after gastric bypass, biliopancreatic diversion and duodenal switch [4], but it occurs also after sleeve gastrectomy [26] and more rarely after adjustable gastric banding $[5,25]$. Menstruating women are more frequently affected [4]. Several factors play a role in causing iron deficiency after bariatric surgery. First, iron absorption occurs mostly in the duodenum and proximal jejunum, the gut sections that are bypassed in some procedures. Second, decreased acid production in the stomach and accelerated gastric emptying impair the reduction of iron from the ferric $\left(\mathrm{Fe}^{3+}\right)$ to the absorbable ferrous state $\left(\mathrm{Fe}^{2+}\right)$. Third, the intake of iron-rich foods (meats, enriched grains and vegetables) is frequently low. Finally the absorption of iron may be inhibited by interaction with other nutritional supplements (calcium) [4, 5]. Prophylactic empiric iron supplementation is recommended after gastric bypass, biliopancreatic diversion, duodenal switch and sleeve gastrectomy [4,5]. Iron is usually included in oral multivitamin and mineral preparations with the inclusion of vitamin $\mathrm{C}$, that is able to increase iron absorption [4] ; they should not be taken along together with calcium supplements.

Vitamin B12: Cobalamin deficiency occurs after surgical procedures (gastric bypass and sleeve gastrectomy) that cause a decreased acid production in the stomach and a reduced availability of intrinsic factor (IF) [4, 26]. Cobalamin stores are usually high and vitamin B12 deficiency is therefore rare in the first year after surgery, but tends to increase with time [4]. Despite the absence of evidence-based recommendations, vitamin B12 supplementation is usually recommended after gastric bypass, sleeve gastrectomy, biliopancreatic diversion and duodenal switch [4]. Absorption of vitamin B12 mostly requires the presence of IF, but approximately $1 \%$ of oral vitamin B12 is passively absorbed even without IF [5]. Therefore, 
Busetto et al.: Practical Recommendations of the Obesity Management Task Force of the European Association for the Study of Obesity for the Post-Bariatric Surgery

Medical Management

an oral dose of 350-500 $\mu \mathrm{g} /$ day is considered sufficient to guarantee the absorption of the daily vitamin B12 requirement $[5,25]$. Alternatively suggested regimens of administration are $1 \mathrm{mg} /$ month intramuscularly, $3 \mathrm{mg}$ every 6 months intramuscularly or $500 \mu \mathrm{g}$ every week intranasally [4].

Folic Acid: Folate deficiency is uncommon after bariatric surgery because folate absorption occurs throughout the entire small bowel [4]. Anyway, folic acid is usually contained in the multivitamin and mineral supplements routinely used in bariatric patients.

Calcium and Vitamin D: Calcium absorption occurs preferentially in the duodenum and proximal jejunum and is facilitated by vitamin $\mathrm{D}$ in an acid environment. Calcium absorption would therefore decrease after any bariatric procedure involving a bypass of the first intestinal loops, reducing gastric acid production and lowering vitamin D levels. Vitamin D is a fatsoluble vitamin absorbed preferentially in the jejunum and ileum. Therefore, a high incidence of vitamin D deficiency (50-60\% of the patients) despite routine supplementation has been reported after biliopancreatic diversion [27, 28], gastric bypass [29] and omega-loop gastric bypass [30]. No significant decreases in vitamin D levels have been observed after sleeve gastrectomy [26] or adjustable gastric banding [31]. The most important consequence of coupled calcium and vitamin D deficiencies is bone demineralisation. Therefore, even in the absence of conclusive evidence concerning the long-term risk of fractures after bariatric surgery, calcium and vitamin D routine supplementation is strongly recommended after gastric bypass and malabsorptive procedures [4-6, 25]. Obese patients frequently present vitamin D deficiency at baseline; this deficiency should be corrected before surgery with an oral vitamin D load [5]. After surgery, the regular consumption of 1,200-2,000 mg/day of elemental calcium along with $400-800 \mathrm{U}$ of vitamin D is recommended [4]. Calcium citrate should be preferred to calcium carbonate because it is better absorbed in the absence of gastric acid [5]. This standard supplementation is frequently insufficient to maintain sufficient vitamin D levels in patients with malabsorption, and much higher oral or parenteral doses may be required. Therefore, the adequacy of calcium and vitamin D supplementation should be checked in any patients, with regular controls of markers of bone mineral metabolism. Supplementation may be considered adequate when levels for serum calcium, bonespecific alkaline phosphatase or osteocalcin, vitamin D, parathyroid hormone (PTH) and 24-hour urinary calcium excretion rates are normal $[4,5]$. Persistently elevated serum PTH levels in the presence of normal vitamin D and inappropriately high serum calcium levels should raise the suspect of a primary hyperparathyroidism. In post-bariatric patients with established osteoporosis pharmacologic treatment with bisphosphonates may be considered. Before starting bisphosphonate treatment, vitamin D deficiency needs to be fully corrected in order to avoid severe hypocalcaemia, hypophosphatemia, and osteomalacia [4]. Intravenous bisphosphonates are the preferred choice because of concerns about low absorption and potential risk of anastomotic ulcer with oral bisphosphonates [6]. Recommended intravenous drugs were zoledronate ( $5 \mathrm{mg}$ once a year) or ibandronate ( $3 \mathrm{mg}$ every 3 months), whereas oral bisphosphonates were alendronate $(70 \mathrm{mg} /$ week), risedronate $(35 \mathrm{mg} /$ week or $150 \mathrm{mg} / \mathrm{month})$ and ibandronate $(150 \mathrm{mg} / \mathrm{month})$ [6]. The effectiveness of both intravenous and oral bisphosphonates in improving bone mineralisation has never been proved specifically in bariatric patients.

Fat-Soluble Vitamins: The absorption of any fat-soluble vitamin (A, E, K, D) is reduced after bariatric procedures causing fat malabsorption and steatorrhoea (biliopancreatic diversion and duodenal switch). Vitamin A deficiency can cause ocular xerosis and night blindness. Vitamin E deficiency can lead to anaemia, ophthalmoplegia and peripheral neuropathy. Vitamin K deficiency can cause easy bleeding. The combined prevalence of these deficiencies is high after malabsorptive procedures [4], and therefore routine fat-soluble 
Busetto et al.: Practical Recommendations of the Obesity Management Task Force of the European Association for the Study of Obesity for the Post-Bariatric Surgery Medical Management

vitamin supplementation is recommended in all patients having undergone biliopancreatic diversion or biliopancreatic diversion with duodenal switch [4].

Thiamine: The human body has a low storage capacity for the water-soluble vitamin thiamine (vitamin B1) and can become rapidly devoid without regular and sufficient intake. Therefore, a short period of persistent vomiting impairing regular food intake can precipitate thiamine deficiency $[5,25]$. Symptomatic thiamine deficiency has been described after a few weeks of intractable vomiting after any bariatric procedure, usually as a consequence of mechanical problems such as stoma stenosis after gastric bypass [32], excessive band tightness or band slippage after gastric banding [33] and stomach oedema with impaired nutrition after sleeve gastrectomy [34]. Cases of thiamine deficiencies have been reported also after biliopancreatic diversion [35]. Peripheral neuropathy or Wernicke's encephalopathy and Korsakoff's psychoses are the typical manifestations of thiamine deficiency [5]. These neurologic symptoms are rapidly aggravating and may cause permanent neurologic deficits. Therefore, oral or parenteral thiamine supplementation (50-100 mg/day) should promptly be considered and started in every bariatric patient suffering from persistent vomiting severe enough to interfere with regular nutrition, even in the absence or before obtaining confirmatory laboratory data $[4,5]$. In symptomatic patients, oral supplementation may be used only after 1-2 weeks of parenteral administration (100 mg/day) and continued until symptom resolution [4]. In case of severe malnutrition with the need for nutrition support, refeeding syndrome should be considered and fluid and electrolyte status should be monitored [36].

Other Micronutrients: Other minerals (zinc, copper, selenium, magnesium, potassium) and vitamin (B6) deficiencies have been described after bariatric surgeries [4, 5, 25]. Routine supplementation with multivitamins and minerals is usually sufficient to prevent clinical problems. If higher doses of single trace elements are needed, timing of administration of these micronutrients should be considered due to the possible interference between elements for intestinal absorption (zinc and iron in particular) [37, 38].

\section{Micronutrient Supplementation and Nutritional Follow-Up}

Suggested daily supplementation for patients with gastric bypass and sleeve gastrectomy includes two adult multivitamin plus mineral supplements (containing iron, folic acid and thiamine), 1,200-1,500 mg of elemental calcium (in diet and as citrated supplement in divided doses), at least 3,000 IU of vitamin D (titrated to therapeutic 25-hydroxyvitamin D levels $>30$ $\mathrm{ng} / \mathrm{ml}$ ), and vitamin B12 titrated to maintain normal levels [6]. Routine supplementation with adequate amounts of fat-soluble vitamins should be added to this regimen after biliopancreatic diversion or duodenal switch [4]. In case of gastric banding, the suggested daily supplementation may be reduced to adult multivitamin plus mineral supplement and at least 3,000 IU of vitamin D (titrated to vitamin D levels) with or without 1,200-1,500 mg of elemental calcium (in diet and as citrated supplement in divided doses) [6].

Routine supplementation does not ensure an absolute prevention of deficiencies over time, mainly because of individual variations in micronutrient absorption, nutritional requirements and compliance. Therefore, periodic laboratory routine surveillance for nutritional deficiencies is recommended, and supplementation should be individualised accordingly in patients with demonstrated micronutrient insufficiencies or deficiencies [6]. A reasonable scheme for minimal periodic nutritional surveillance after bariatric procedures is proposed in table 6 [39]. Dual-energy X-ray absorptiometry (DEXA) should be performed before surgery and bi-annually thereafter to monitor bone mineral density in patients with gastric bypass, biliopancreatic diversion or duodenal switch [6]. However, the possibility to perform DEXA and its reliability before surgery may be risky in very obese patients. 
Busetto et al.: Practical Recommendations of the Obesity Management Task Force of the European Association for the Study of Obesity for the Post-Bariatric Surgery Medical Management

Table 6. Minimal periodic surveillance for nutritional deficiencies after bariatric surgery

\begin{tabular}{|c|c|c|c|c|}
\hline & AGB & SG & RYGB & $\mathrm{BPD}-\mathrm{BPD} / \mathrm{DS}$ \\
\hline Timing & $\begin{array}{l}\text { every } 6 \text { months in } \\
\text { the first year } \\
\text { every } 12 \text { months } \\
\text { thereafter }\end{array}$ & $\begin{array}{l}\text { every } 3-6 \text { months in } \\
\text { the first year } \\
\text { every } 12 \text { months } \\
\text { thereafter }\end{array}$ & $\begin{array}{l}\text { every } 3-6 \text { months in } \\
\text { the first year } \\
\text { every } 12 \text { months } \\
\text { thereafter }\end{array}$ & $\begin{array}{l}\text { every } 3 \text { months in } \\
\text { the first year } \\
\text { every } 6-12 \text { months } \\
\text { thereafter }\end{array}$ \\
\hline Assessment & $\begin{array}{l}\text { CBC, platelets } \\
\text { electrolytes } \\
\text { iron, ferritine } \\
\text { vitamin B12 } \\
\text { folate } \\
\text { vitamin D } \\
\text { PTH }\end{array}$ & $\begin{array}{l}\text { CBC, platelets } \\
\text { electrolytes } \\
\text { iron, ferritine } \\
\text { vitamin B12 } \\
\text { folate } \\
\text { vitamin D } \\
\text { PTH }\end{array}$ & $\begin{array}{l}\text { CBC, platelets } \\
\text { Electrolytes } \\
\text { iron, ferritine } \\
\text { vitamin B12 } \\
\text { folate } \\
\text { vitamin D } \\
\text { PTH } \\
\text { 24-H U-calcium } \\
\text { osteocalcin }\end{array}$ & $\begin{array}{l}\text { CBC, platelets } \\
\text { electrolytes } \\
\text { iron, ferritine } \\
\text { vitamin B12 } \\
\text { folate } \\
\text { vitamin D } \\
\text { PTH } \\
\text { 24-H U-calcium } \\
\text { osteocalcin } \\
\text { vitamin A } \\
\text { vitamin E } \\
\text { INR } \\
\text { albumin } \\
\text { prealbumin }\end{array}$ \\
\hline
\end{tabular}

$\mathrm{AGB}=$ Adjustable gastric banding; $\mathrm{SG}=$ sleeve gastrectomy; RYGB = gastric bypass; $\mathrm{BPD}=$ biliopancreatic diversion; $\mathrm{BPD} / \mathrm{DS}=$ biliopancreatic diversion with duodenal switch. $\mathrm{CBC}=$ complete blood count; $\mathrm{PTH}=$ intact parathyroid hormone; 24-H U-calcium = 24-hour urinary calcium (modified [39]).

\section{Management of Co-Morbidities}

Bariatric surgery has profound effects on obesity-related co-morbidities. These effects are in general positive, but they can occur very rapidly, requiring prompt modifications and adjustments of medical therapy. Moreover, the status of co-morbidities and their evolution should be monitored both in the short and in the long term after surgery. In this section, firstlevel information about post-surgical management of type 2 diabetes, obstructive sleep apnoea (OSA), dyslipidaemia and hypertension is included. A short list of graded clinical practical recommendations on management of co-morbidities after bariatric surgery is reported in table 7.

\section{Type 2 Diabetes}

According to the latest IFSO Global Registry Report, 22\% of patients undergoing bariatric surgery were on medications for type 2 diabetes before surgery (inter-country variation 7.4-63.2\%) [40]. Bariatric surgery has been shown to improve metabolic status and to reduce micro- and macrovascular complications and cardiovascular deaths in patients with type 2 diabetes [1, 41-43]. On the other hand, poor pre-operative glucose control can lead to an increased risk of peri-operative complications [6], and some studies suggest that optimal glucose control prior to surgery may improve the chances of diabetes remission after surgery [44]. Moreover, higher post-operative glucose levels can lead to increased morbidity [45]. Therefore, good blood glucose control pre- and post-bariatric surgery is highly recommended. In general, caution should be the guide in treatment, with close follow-up of glucose levels before and immediately after surgery, until eating habits and food intake stabilise. This is due 
Busetto et al.: Practical Recommendations of the Obesity Management Task Force of the European Association for the Study of Obesity for the Post-Bariatric Surgery Medical Management

Table 7. List of graded clinical practical recommendations for the management of major obesity-related comorbidities after bariatric surgery

\begin{tabular}{lll}
\hline Recommendations & $\begin{array}{l}\text { Level of } \\
\text { evidence }\end{array}$ & $\begin{array}{l}\text { Grade of } \\
\text { recommendation* }\end{array}$ \\
\hline
\end{tabular}

Type 2 diabetes

Bariatric surgery has profound effects on diabetes and can lead to prompt modifications and adjustments of medical therapy.

Metabolic control should be optimized in preparation for a bariatric procedure. HbA1c levels of 6.5-7\%, fasting glucose levels $<110 \mathrm{mg} / \mathrm{dl}$ and $2 \mathrm{~h}$ post-load glucose $<140 \mathrm{mg} / \mathrm{dl}$ should be targeted. In patients with long lasting diabetes, diabetes complications and poor glucose control, $\mathrm{HbA} 1 \mathrm{c}$ levels $<8 \%$ are considered acceptable.

Glitazones, glinides and dipeptidyl-dipeptidase 4 inhibitors (DDP4i) should be discontinued $24 \mathrm{~h}$ before surgery with a reduction of basal insulin dosage to 0.3 units $/ \mathrm{kg}$. Metformin should be discontinued on the day of surgery.

On the day of surgery, glucose levels should be targeted at $<140 \mathrm{mg} / \mathrm{dl}$ and short acting insulin should be used according to a correction factor of one unit of insulin for every $40 \mathrm{mg} / \mathrm{dl}$ above the level of 140 $\mathrm{mg} / \mathrm{dl}$.

In hospital, target glucose values should be $140-180 \mathrm{mg} / \mathrm{dl}$. if values are $>180 \mathrm{mg} / \mathrm{dl}$ in two consecutive tests basal insulin at a dose of 0.1 units/kg should be prescribed.

Metformin can be reassumed from the 3rd day after surgery providing 3 that renal function has been controlled at a dosage of $850 \mathrm{mg}, 1-2$ times daily. After gastric bypass surgery, biological availability of metformin increases by $50 \%$, and therefore reduced dosages should be prescribed.

In the first 7-10 days after surgery, treatment should be directed toward fasting glucose values and patients should be instructed to test sugar at least twice a day fast in the morning (target values: 100-120 $\mathrm{mg} / \mathrm{dl}$ ) and during the day (less than $180 \mathrm{mg} / \mathrm{dl} 2 \mathrm{~h}$ after a meal). In the first 7-10 days after surgery, use of sulfonylureas and medications that increase the risk of hypoglycaemia should be avoided.

For patients still requiring insulin during their post-operative hospital staying, basal insulin should be continued at discharge, with strict glucose monitoring and tapering of insulin units for avoidance of hypoglycaemia.

In cases of complicated glucose control in the early post-operative phase, consultation with an endocrinologist should be considered. After the first early post-operative period, standard diabetes guidelines should be followed for the management of patients still requiring pharmacologic anti-diabetic treatment after bariatric surgery.
1

A

2

C

$\mathrm{D}$

D

D

D

3

D

D

D

3

D

4

D

Table 7 continued on next page 
Table 7.Continued

Busetto et al.: Practical Recommendations of the Obesity Management Task Force of the European Association for the Study of Obesity for the Post-Bariatric Surgery Medical Management

\begin{tabular}{lll}
\hline Recommendations & $\begin{array}{l}\text { Level of } \\
\text { evidence }\end{array}$ & $\begin{array}{l}\text { Grade of } \\
\text { recommendation* }\end{array}$ \\
\hline $\begin{array}{l}\text { Obstructive sleep apnoea } \\
\text { Patients with Obstructive Sleep Apnoea should continue CPAP or } \\
\text { BiPAP therapy immediately after surgery and for 3-6 months post- } \\
\text { surgery. Thereafter, patients should be reviewed by the respiratory } \\
\text { physician in order to determine whether the BiPAP/CPAP pressures } \\
\text { need to be adjusted and if a new sleep-respiratory assessment should } \\
\text { be undertaken. }\end{array} \quad$ D & \\
\hline $\begin{array}{l}\text { Dyslipidaemia } \\
\text { Lipid-lowering medications should not be stopped after surgery } \\
\text { unless clearly indicated. Patients with dyslipidaemia and on lipid- } \\
\text { modifying medications should be have lipid profiles and } \\
\text { cardiovascular risk status reassessed periodically. }\end{array}$ & D \\
\hline
\end{tabular}

Hypertension

In the first week after surgery, blood pressure tends to go down and 4 $4 \quad \mathrm{D}$ should be monitored actively, with prompt adjustment of blood pressure medications to the new therapeutic needs. Avoidance of diuretics may be suggested in this phase for the high risk of dehydration.

Continued surveillance of blood pressure is needed after surgery, because of the high risk of recurrence over time. Treatment of hypertension in the long-term should adhere to current general guidelines, possibly avoiding anti-hypertensive medications with a known unfavourable effect on body weight. In the patients in whom hypertension have resolved, continued surveillance should be guided by recommended screening guidelines for the specific age group.

*For the grading system refers to table 1.

to the fear of hypoglycaemia on one hand, and to the risk of poor glucose control on the other. The guidelines detailed below can direct medical treatment. However, individual considerations and follow-up are needed for each patient.

Pre-Operative Glucose Control: Ideally, metabolic control should be optimised in patients with obesity and type 2 diabetes in preparation for a bariatric procedure. HbA1c levels of $6.5-7 \%$, fasting glucose levels $<110 \mathrm{mg} / \mathrm{dl}$ and 2 -hour post-load glucose $<140 \mathrm{mg} / \mathrm{dl}$ should be targeted. In patients with long lasting diabetes, diabetes complications and poor glucose control, HbA1c levels $<8 \%$ are considered acceptable, but levels $>8 \%$ calls for clinical judgement regarding pre-operative medical treatment [6]. For patients treated with a lowcalorie diet before surgery, cessation of sulfonylureas and GLP-1 receptor agonist, reduction of basal insulin by half and reduction or cessation in the usage of short-acting insulin should be considered, with strict follow-up of glucose levels [46].

Peri-Operative Diabetes Management: Glitazones, glinides and dipeptidyl-dipeptidase 4 inhibitors (DDP4i) should be discontinued $24 \mathrm{~h}$ before surgery, with a reduction of basal insulin dosage to $0.3 \mathrm{U} / \mathrm{kg}$ of body weight. The continuation of the regular medications on the day before surgery with a reduction of basal insulin dosage to $0.3 \mathrm{U} / \mathrm{kg}$ of body weight can be also considered [47]. Metformin should be discontinued on the day of surgery. On the day of 
Busetto et al.: Practical Recommendations of the Obesity Management Task Force of the European Association for the Study of Obesity for the Post-Bariatric Surgery Medical Management

Table 8. A simple scheme for basal insulin prescription at discharge after bariatric surgery

\begin{tabular}{ll}
\hline Basal insulin needs before discharge & Dose of basal insulin prescribed at discharge \\
\hline 10 units or less of basal insulin & the same dose should be continued at discharge \\
$10-19$ units of basal insulin & 10 units should be continued at discharge \\
$20-29$ units of basal insulin & 15 units should be continued at discharge \\
$30-39$ units of basal insulin & 20 units should be continued at discharge \\
$40-49$ units of basal insulin & 30 units should be continued at discharge \\
50 units or more of basal insulin & 40 units should be continued at discharge \\
\hline
\end{tabular}

surgery, glucose levels should be targeted at $<140 \mathrm{mg} / \mathrm{dl}$ and short-acting insulin should be used according to a correction factor of one unit of insulin for every $40 \mathrm{mg} / \mathrm{dl}$ above the level of $140 \mathrm{mg} / \mathrm{dl}$. From the day following the operation until discharge from the hospital, similar to the routine treatment for a hospitalised patient, target glucose values should be 140-180 $\mathrm{mg} / \mathrm{dl}$ with basal insulin at a dose of $0.1 \mathrm{U} / \mathrm{kg}$ prescribed if values are above $180 \mathrm{mg} / \mathrm{dl}$ in two consecutive determinations [48]. In cases of complicated glucose control, consultation of an endocrinologist should be considered.

Early Post-Operative Management (7-10 Days after Surgery): During this period, patients are required to consume fluids, and the caloric intake is minimal. Therefore, in most cases, glycaemic peaks after meals are reduced considerably. For this reason, treatment is directed predominantly toward fasting glucose values. Patients should be instructed to test blood glucose at least twice a day: in fast in the morning and during the day, with target values of $100-120 \mathrm{mg} / \mathrm{dl}$ in fast and less than $180 \mathrm{mg} / \mathrm{dl} 2 \mathrm{~h}$ after a meal [47]. For patients who were treated with oral diabetes medications prior to surgery and who did not need these medications post-operatively, due to normal glucose levels, glucose control can be followed without medical treatment. If glucose levels are consistently high post-operatively, also after weight reduction, treatment should be adjusted again, with the treatment of choice being metformin [47]. After surgery, the use of sulfonylureas and medications that increase insulin secretion should be avoided due to the increased risk of hypoglycaemia [6]. Metformin can safely be administered again from the 3rd day after surgery providing that renal function has been controlled at a dosage of $850 \mathrm{mg}, 1-2$ times daily [47]. After gastric bypass surgery, biological availability of metformin increases by $50 \%$, and therefore reduced dosages should be prescribed. In cases of intolerance to metformin, low dosages of basal insulin can be recommended. Whenever the blood glucose control during the early post-surgical period is difficult, a combination of low-dose basal insulin and DPP4 inhibitors can be considered, as a response to post-prandial glucose levels and taking into account renal function. For patients still requiring insulin during their post-operative hospitalisation, basal insulin should be continued at discharge, with strict glucose monitoring and tapering of insulin units to avoid hypoglycaemia. A simple scheme for prescription of the basal insulin dosage at discharge according to the basal insulin needs during hospitalisation is presented in table 8 , but alternative regimens can be used with emphasis on patients' education and self-monitoring. For patients who need higher dosages of insulin during post-surgical hospitalisation, a prescription of 2-3 $\mathrm{U}$ of short-acting insulin around the three main meals should be considered. Due to the complexity of diabetes treatment in these patients, treatment should be assessed and adjusted at 7-10 days after surgery by an experienced physician. In general, caution should be taken to avoid hypoglycaemia in these patients, especially during the night; therefore, insulin dosages should be as low as possible and corrected as necessary. 
Busetto et al.: Practical Recommendations of the Obesity Management Task Force of the European Association for the Study of Obesity for the Post-Bariatric Surgery Medical Management

Long-Term Post-Operative Diabetes Management: After the first early post-operative period, standard diabetes guidelines should be followed in the management of patients still requiring pharmacologic anti-diabetic treatment after bariatric surgery. For patients in good metabolic control and not requiring glucose-lowering medications after surgery (complete diabetes remission), treatment goals for co-morbid conditions and screening for microvascular complications should be the same as those for patients with diabetes [49]. With prolonged remission ( $>5$ years), treatment goals appropriate for patients without diabetes can be considered, as long as there is no recurrence of diabetes and no cardiovascular disease, and screening at a reduced frequency depending on the status of each complication. With prolonged remission, screening for a particular complication should be completely stopped only in absence of that complication [49].

\section{OSA}

Definitions and Diagnosis of OSA: OSA is a common sleep-related breathing disorder caused by nocturnal upper airway obstruction, resulting in arterial hypoxia and sleep fragmentation. The major risk factors for OSA are obesity, older age and male gender. Individuals suffering from OSA have increased risk of several adverse health outcomes, including allcause mortality, traffic accidents, hypertension, type 2 diabetes, coronary heart disease, arrhythmia, heart failure and stroke [50-53]. The apnoea-hypopnea index (AHI) is the number of complete cessations (apnoea $\geq 10 \mathrm{~s}$ ) and partial obstructions (hypopneas) of breathing occurring per hour of sleep. OSA is defined as an AHI of at least 5 events/h. An AHI of $\geq 5$ to $<15$ events/h is defined as mild OSA, of $\geq 15$ to $<30$ events/h as moderate OSA and of $\geq 30$ events/h as severe OSA [50]. Polysomnography, the gold standard method to diagnose OSA, provides detailed information on sleep and respiratory and gas exchange abnormalities [50]. However, less resource-intensive and validated methods such as home-based sleep monitors may be suitable for clinical practice [54]. Snoring is the most frequent night time symptom of OSA, but it has poor predictive value because snoring without OSA is common in the general population. Other nocturnal symptoms are choking or gasping, frequent arousals, nocturia and excessive sweating [50]. Excessive daytime sleepiness is a commonly reported symptom, which can lead to accidents and poor quality of life. Other daytime symptoms include increased appetite, memory impairment, personality changes, irritability, morning headache, anxiety and depression [50].

Prevalence among Patients Undergoing Bariatric Surgery: OSA is underdiagnosed and probably the most common co-morbidity among patients preparing for obesity surgery [53, $55,56]$. Although the literature is sparse, approximately 2 out of 3 patients undergoing sleep registration before surgery have OSA, of which 2 out of 3 have moderate or severe OSA requiring specific treatment $[53,55,56]$. A recently published large Dutch cohort study demonstrated that approximately one-third of 1,358 consecutive patients preparing for bariatric surgery had moderate to severe OSA (AHI $\geq 15 / \mathrm{h}$ ) [56].

Management: Treatment with continuous positive airway pressure (CPAP) or mandibular advancement devices (MADs) is usually indicated in patients with moderate to severe OSA and in those with mild OSA and clinical symptoms. CPAP treatment is associated with significant improvements in OSA-related symptoms [50]. However, common adverse effects of CPAP and MADs include oral or nasal dryness, irritation and pain [50]. CPAP treatment might also be insufficient or not tolerated by some patients with concurrent chronic obstructive pulmonary disease (COPD) and daytime hypercapnia and/or nocturnal hypoxia. These patients suffer from a COPD-OSA overlap syndrome and may benefit from bi-level positive airway pressure (BiPAP) treatment [57]. BiPAP treatment might also an effective therapeutic alternative for CPAP in patients not responsive or intolerant to CPAP [58]. In patients with obesity, weight loss is the most important alternative treatment for OSA. A recent review and 
Busetto et al.: Practical Recommendations of the Obesity Management Task Force of the European Association for the Study of Obesity for the Post-Bariatric Surgery Medical Management

meta-analysis demonstrated that obesity surgery was followed, on average, by a large reduction in AHI (29 events/h; 95\% CI 22-37 events/h) [59]. However, although bariatric surgery significantly ameliorates OSA, it does not completely resolve the disease in all patients. A recent Dutch observational study of 205 patients undergoing gastric bypass with moderate to severe obesity before surgery revealed that approximately three-quarters of the patients with moderate to severe OSA before surgery had no or mild OSA after surgery, whilst one out of four still had moderate to severe OSA [60]. The strongest predictor of lack of remission was a pre-operative $\mathrm{AHI} \geq 30 / \mathrm{h}$ (OR 5.7; 95\% CI 2.4-13.2). Further, weight regain and increasing age may lead to worsening of symptoms and need of additional treatment (e.g. CPAP) during the years following surgery.

Follow-Up of OSA after Bariatric Surgery: Health providers should pay particular attention to patients in whom OSA had been diagnosed before surgery. Although weight loss ameliorates symptoms in the majority of patients, many patients still have symptoms and need supplementary treatment with CPAP or MADs. In addition, increasing age and weight regain increase the risk of relapse or new-onset OSA. Accordingly, weight stabilisation after surgery is also important to prevent OSA or worsening of OSA. Recent guidelines suggest that patients with known OSA should bring their CPAP or BiPAP devices with them for surgery and continue to use it for 3-6 months post-surgery [61]. Thereafter, patients should be reviewed by the respiratory physician in order to determine whether the BiPAP /CPAP pressures need to be adjusted and if a new sleep respiratory assessment should be undertaken.

\section{Dyslipidaemia}

Dyslipidaemia and Bariatric Surgery: Dyslipidaemias are defined as abnormalities in the serum levels of lipids including high total cholesterol, high triglycerides, low HDL-cholesterol and elevated LDL-cholesterol [62]. Furthermore, most patients undergoing bariatric surgery have insulin resistance, metabolic syndrome and/or type 2 diabetes and therefore present with a lipid profile characterized by increased levels of atherogenic small-dense LDL particles $[63,64]$. Importantly, while lowering LDL-cholesterol is associated with reduced risk of cardiovascular disease, it remains unclear whether treatment of high triglyceride level and low HDLcholesterol improves cardiovascular outcomes [64]. Weight loss has beneficial effects on lipids and amplifies the benefits of dietary treatment, resulting in a $20 \%$ decrease in triglycerides, a $15 \%$ reduction in LDL-cholesterol and an 8-10\% increase in HDL-cholesterol [65]. Therefore, the large reduction in body fat mass after bariatric surgery leads to beneficial changes in serum lipids (total-cholesterol, LDL-cholesterol, HDL-cholesterol and triglycerides), with the greater the body weight loss, the greater the improvement in dyslipidaemia [66, 67]. Moreover, bariatric surgery may affect serum lipids by alternative mechanisms, including alteration of lipid metabolism, gastro-intestinal lipid absorption, bile acid metabolism, gut microbiota and gut hormones $[66,67]$. Some bariatric procedures augment the beneficial effects of weight loss by reducing the absorption of cholesterol. Apparently only RYGB, but not gastric banding [68] or gastric sleeve gastrectomy [69], is associated with reduced absorption of cholesterol. A recent systematic review and meta-analysis demonstrated that LDL-cholesterol was reduced significantly after gastric bypass $(0.64 \mathrm{mmol} / \mathrm{l})$ and biliopancreatic diversion $(1.17 \mathrm{mmol} / \mathrm{l})$, while the LDL-lowering effects of gastric banding $(0.23 \mathrm{mmol} / \mathrm{l})$ and sleeve gastrectomy $(0.20$ $\mathrm{mmol} / \mathrm{l})$ were small or non-significant [70]. To conclude, the beneficial effect of bariatric surgery on triglyceride and HDL-cholesterol levels seems to be weight loss-dependent while the improvement in LDL-cholesterol levels after gastric bypass surgery is at least partly weight loss-independent. RYGB may influence lipid levels also by decreasing dietary preference for high-fat and increases preference for low-fat food [71], although a very small proportion of patients undergoing RYGB in a controlled clinical study fulfilled the recommendation of less than $10 \%$ of energy intake from saturated fat after surgery [72]. 
Busetto et al.: Practical Recommendations of the Obesity Management Task Force of the European Association for the Study of Obesity for the Post-Bariatric Surgery Medical Management

Surveillance and Treatment of Dyslipidaemia after Bariatric Surgery: On average, serum total-cholesterol, LDL-cholesterol, HDL-cholesterol and triglycerides decline during the first 6 weeks after gastric bypass $[66,73]$. Several studies demonstrated that the LDL-cholesterol and triglyceride levels were reduced until 1 year and then stabilized in parallel with the period of maximum weight loss (1-2 years), while HDL-cholesterol increases from 6 weeks to 1-2 years above the baseline level $[66,73]$. In general, the proportion of patients taking lipid-lowering drugs after bariatric surgery tends to reduce [74]. Schauer et al. [75] reported that the number of patients receiving lipid-lowering agents decreased from $86 \%$ to $27 \% 1$ year after RYGB. Although bariatric surgery is associated with significant improvement of several cardiovascular risk factors, a large proportion of patients undergoing bariatric surgery may remain at high risk for cardiovascular disease. Accordingly, regular monitoring of serum lipids and therapeutic strategies to prevent cardiovascular disease are recommended $[6,61$, 64]. Recent guidelines underscore that the effect of weight loss on dyslipidaemia is variable and incomplete; therefore, lipid-lowering medications should not be stopped unless clearly indicated [6], and patients with dyslipidaemia and on lipid-modifying medications should be re-assessed by performing fasting lipid profiles periodically, including re-assessment of cardiovascular risk status [61]. The European Society of Cardiology and European Atherosclerosis Society recently published guidelines for the management of dyslipidaemias, including practical evidence-based advices that may be helpful for bariatric physicians [64]. According to the guidelines, the LDL-cholesterol goal is $<2.6 \mathrm{mmol} / \mathrm{l}$ in high-risk patients and $<3.0 \mathrm{mmol} / \mathrm{l}$ in people with moderate total cardiovascular risk [64]. To reach these goals, weight stabilisation after weight loss and healthy nutrition are of major importance. However, treatment with statins should be initiated if treatment targets are not met on lifestyle intervention [64]. Since the long-term effect of bariatric surgery on the absorption and pharmacokinetics of statins is largely unknown [76], patients on statins should be treated with the lowest dose possible while monitoring the plasma lipid profile $[76,77]$. One of the few studies addressing this issue demonstrated that the systemic exposure of atorvastatin showed a significant change over time after bariatric surgery, albeit with large inter- and intra-individual variations. The findings indicate that patients using atorvastatin or drugs with similar pharmacokinetic properties should be monitored closely for both therapeutic effects and adverse events during the first years after gastric bypass and duodenal switch [77].

\section{Hypertension}

Surveillance and Treatment of Hypertension after Bariatric Surgery: According to a large meta-analysis of surgical series, about one-third (35.4\%) of patients undergoing bariatric surgery presented with hypertension before the procedure [41]. On the short term, weight loss following bariatric surgery was associated with a significant improvement of hypertension [41]. In the long term, results seem to be less brilliant, with some patients having recurrence of hypertension over time [1]. Therefore, lowering of blood pressure medications is frequently needed in the first period after surgery, when blood pressure tends to go down, but continued surveillance of blood pressure is also needed because of the high risk of recurrence over time. In the first week after surgery, blood pressure should be monitored actively, and blood pressure medications should be adjusted to the new therapeutic needs. Avoidance of diuretics may be suggested in this phase due to the high risk of dehydration. Treatment of hypertension in the long term should adhere to current general guidelines, possibly avoiding anti-hypertensive medications with a known unfavourable effect on body weight [78]. In patients in whom hypertension have resolved, continued surveillance should be guided by recommended screening guidelines for the specific age group [4]. 
Busetto et al:: Practical Recommendations of the Obesity Management Task Force of the European Association for the Study of Obesity for the Post-Bariatric Surgery

Medical Management

Table 9. List of graded clinical practical recommendations for pharmacotherapy after bariatric surgery

\begin{tabular}{lll}
\hline Recommendations & $\begin{array}{l}\text { Level of } \\
\text { evidence }\end{array}$ & $\begin{array}{l}\text { Grade of } \\
\text { recommendation* }\end{array}$ \\
\hline $\begin{array}{l}\text { The potential effects and consequences that any bariatric procedure } \\
\text { may have on absorption and action of medications should be carefully } \\
\begin{array}{l}\text { considered before surgery, especially for medications where changes in } \\
\text { blood levels may have critical effects on patients conditions or can } \\
\text { cause significant adverse events }\end{array}\end{array}$ \\
\hline
\end{tabular}

After surgery, plasma drug levels should be checked more frequently $3 \quad$ C for those drugs requiring periodic plasma levels control.

If possible, liquid oral dosage forms should be used instead of solid $4 \quad$ D dosage forms for at least two months after surgery.

NSAIDs, salicylates, corticosteroids and other drugs that may cause 3 D

gastric damage should be avoided.

Oral contraceptives should be replaced by non-oral contraceptives due 3 D

to reduced efficacy after gastric bypass and bilio-pancreatic diversion.

*For the grading system refers to table 1 .

\section{Pharmacotherapy after Bariatric Surgery}

Bariatric surgeries induce substantial anatomical and physiological changes in the gastrointestinal tract and elsewhere, any one of which may affect drug pharmacokinetics in different directions. Absorption of drugs is predominantly affected, but also tissue distribution, drug metabolism and elimination may change. Moreover, it is difficult to disentangle the specific effects of surgery and weight loss on bioavailability of the drugs, and it is important to note that there are not only important differences in the effects of different procedures but also considerable inter- and even intra-individual variations in drug absorption over time. This complex challenge is currently unmet by the limited data that exists on this subject [79]. There is an urgent need for further in vitro, in vivo and clinical research in order to understand the effects of bariatric surgeries on drug pharmacokinetics and the mechanisms that underlie these processes. In the meantime, awareness to this important issue must be instilled to medical professionals, including physicians, pharmacists, nurses and dieticians. Patients should be closely monitored in order to evaluate the short- and long-term safety and efficacy of their drug regimen. In this section, first-level information about pharmacotherapy after bariatric surgery is included, and a short list of related graded clinical practical recommendations is reported in table 9.

\section{Practical Recommendations for Pharmacotherapy after Bariatric Surgery}

The potential effects and consequences that any bariatric procedure may have on absorption and action of medications should be carefully considered before surgery, especially for medications where changes in blood levels may have critical effects on patients' conditions or can cause significant adverse events, e.g. anticoagulants, anti-epileptics, drugs for Parkinson's disease, drugs for autoimmune conditions etc. [79]. After surgery, plasma drug levels should be checked more frequently for those drugs requiring periodic plasma level control [79]. When discharged from the hospital, patients should be carefully instructed on the modifications of their medication regimen, including changes in prescription drugs, 
Busetto et al.: Practical Recommendations of the Obesity Management Task Force of the European Association for the Study of Obesity for the Post-Bariatric Surgery Medical Management

over-the-counter drugs, nutrient supplements and homeopathic drugs. Involvement of pharmacists as advisors in the drug treatment is beneficial for both surgeons and patients [80]. If possible, oral liquid-dosage forms should be used instead of solid-dosage forms for at least 2 months after surgery. However, it is important to ensure that the liquid-dosage form does not contain absorbable sugars, in light of the risk for dumping syndrome [81]. Alternatively, non-oral formulations can be used. In cases where only solid-dosage formulations of the drug exist, it may be considered to open the pills and spread the powder in liquid prior to ingestion, but only according to package insert or available company data. It is worthwhile to note that caution should be taken with extended-release dosage forms because quite often they cannot be crushed. Anti-diabetics drugs with a high risk of hypoglycaemia, such as sulfonylureas and glinides, should be discontinued, and insulin doses should be adjusted. Metformin may be continued until normal glucose levels are achieved and maintained [6], but metformin doses may need to be reduced due to increased absorption [82] (see 'Type 2 Diabetes' above). Caution should be applied when administering diuretics post-operatively, as the combined diuretic effect of the drugs and the operation may cause dehydration [83]. NSAIDs, salicylates, corticosteroids and other drugs that may cause gastric damage should be avoided $[84,85]$. Oral contraceptives should be replaced by non-oral contraceptives due to reduced efficacy after gastric bypass and biliopancreatic diversion. However, contraceptive patches may be less effective in patients with obesity, and caution with the use of contraceptive agents is necessary after all bariatric surgeries $[6,86]$. Patients that underwent bariatric surgery are more likely to develop gallstones. Hence, drugs that increase the risk for the formation of gallstones, such as gemfibrozil or octreotide, should be avoided [87]. Special attention should be paid to drugs that require acidic environment or food in order to be adequately absorbed, such as carbamazepine, phenytoin and selegiline [79]. Finally, nutrient supplements (iron, calcium and multivitamins) are regularly prescribed in patients that underwent bariatric surgeries in order to prevent deficiencies, but they can raise the risk for drug-nutrient interactions and decrease the absorption of some drugs [79].

\section{Pregnancy after Bariatric Surgery}

The majority of patients undergoing bariatric surgery are women, and up to $80 \%$ of women are of child-bearing age. Obesity per se is associated with adverse pregnancy outcomes, including gestational diabetes mellitus (GDM), pregnancy-induced hypertension and longterm vascular dysfunction, miscarriages, preeclampsia, thromboembolism, intrauterine growth restriction (IUGR) and post-partum haemorrhage [88, 89]. In addition, the rate of caesarean sections, co-morbidities and failure of epidural analgesia augment with increasing BMI, with the risk being particularly high in obesity class III pregnant women (BMI $>40$ $\mathrm{kg} / \mathrm{m}^{2}$ ) [88]. Pre-pregnancy obesity is also associated with increased health risks for the offspring, such as foetal defects, congenital anomalies, pre-mature birth, stillbirth, large for gestational age (LGA) and shoulder dystocia [88]. Furthermore, obesity is associated with menstrual cycle dysregulation, anovulation and infertility; fertility and conception hence constitute major motivators for women with obesity and associated infertility to undergo bariatric surgery $[90,91]$.

Weight loss following bariatric surgery leads to improved sex hormone profiles and improvement of metabolic and hormonal changes associated with polycystic ovarian syndrome (PCOS), thereby increasing fertility [92-94]. For instance, Legro et al. [93] demonstrated follicular phase shortening, reduction in android fat and improved female sexual function in women post-RYGB. A study looking at PCOS following RYGB demonstrated improvements in hirsutism, type 2 diabetes mellitus and fertility [94]. Following bariatric 
Busetto et al.: Practical Recommendations of the Obesity Management Task Force of the European Association for the Study of Obesity for the Post-Bariatric Surgery Medical Management

Table 10. List of graded clinical practical recommendations for the management of pregnancy after bariatric surgery

\begin{tabular}{lll}
\hline Recommendations & $\begin{array}{l}\text { Level of } \\
\text { evidence }\end{array}$ & $\begin{array}{l}\text { Grade of } \\
\text { recommendation* }\end{array}$ \\
\hline $\begin{array}{l}\text { Pregnancy is not recommended in the first 12-18 months following } \\
\text { bariatric surgery. }\end{array}$ & 3 & $\mathrm{D}$ \\
\hline $\begin{array}{l}\text { Antenatal care should be offered at a specialised centre with experience } \\
\text { in pregnancy following bariatric surgery, via a specialist } \\
\text { multidisciplinary antenatal care team. }\end{array}$ & 4 \\
\hline
\end{tabular}

Micronutrient supplementation should be provided to all women who 3 D are pregnant following bariatric surgery, in the form of a prenatal multivitamin preparation, B12 injections and oral calcium supplements.

Screening for gestational diabetes should be offered, however the 4 $\mathrm{D}$ conventional oral glucose tolerance test should be avoided. Serial capillary glucose monitoring should be used as an alternative.

Women presenting with abdominal pain in pregnancy should be offered 3 urgent expert assessment, particularly for complications related to the primary bariatric surgical procedure.

*For the grading system refers to table 1.

surgery, fertility can rapidly improve, even in previously anovulatory women [95]. A study following up women after various bariatric procedures (intragastric balloon, gastric banding, sleeve gastrectomy and RYGB) reported that the amount of weight loss and BMI were the key determinants of fertility, rather than procedure type [96]. Hence, pregnancy after bariatric surgery is not rare. In this section, first-level information on pregnancy after bariatric surgery is included. A short list of graded clinical practical recommendations on the management of pregnancy after bariatric surgery is given in table 10 .

\section{Benefits and Risks of Pregnancy after Bariatric Surgery}

Currently available data suggests that pregnancy following bariatric surgery is associated with improved maternal and foetal outcomes, compared to women with untreated obesity $[97,98]$. However, there are concerns with regard to conceiving during the period of rapid weight loss seen in the first 12-24 months following bariatric surgery, as this period has been associated with higher rates of nutritional deficiencies and obstetric complications [99]. In a multicentre study from Spain including 168 pregnancies in 112 women, a higher stillbirth rate was seen in pregnancies occurring in the first year post-surgery [100]. Current guidelines hence recommend delaying pregnancy for at least 12 months following surgery [6, 101, 102].

Reduced rates of GDM and hypertension have been reported in mothers after bariatric surgery $[97,103-105]$. In addition, a reduced incidence of macrosomia has been shown in neonates born to mothers who had undergone bariatric surgery $[103,105]$. Emerging data suggests that miscarriage rates, which are high in women with untreated obesity, may be lower following bariatric surgery [106-108]. A retrospective study from Denmark in which 339 women who had received bariatric surgery (83\% RYGB and 17\% gastric bands) were 
Busetto et al.: Practical Recommendations of the Obesity Management Task Force of the European Association for the Study of Obesity for the Post-Bariatric Surgery Medical Management

Table 11. Effects of bariatric surgery on maternal and foetal outcomes [112-114]

\begin{tabular}{|c|c|c|c|}
\hline Maternal outcomes & Risk & Foetal outcomes & Risk \\
\hline Gestational diabetes & reduced & small for gestational age & increased \\
\hline Gestational hypertension & reduced & premature labour & increased \\
\hline Miscarriage & limited data & low birthweight & increased \\
\hline Post-partum haemorrhage & limited data & large for gestational age & reduced \\
\hline Pre-eclampsia & reduced & perinatal mortality & no difference \\
\hline
\end{tabular}

matched to 1,277 untreated obese women for pre-pregnancy BMI, age, parity, date of delivery and smoking status [109]. The study investigators reported that infants born to women after bariatric surgery had lower birth weights, shorter gestation, a reduced risk of being LGA and a higher risk of being small for gestational age (SGA) [109]. A further large retrospective study from Sweden compared pregnancy complications and outcomes in 2,562 women with a previous history of bariatric surgery (including vertical banded gastroplasty, RYGB and banding) to 12,379 controls matched for age, parity, early pregnancy BMI, smoking status and year of delivery [110]. An increased risk for SGA births and pre-term delivery but a reduced risk of LGA infants was seen after bariatric surgery, [110]. A more recent retrospective study from Sweden, compared pregnancy outcomes in 596 mothers who had undergone bariatric surgery (98\% RYGB) to 2,356 controls with comparable BMI, age, parity, smoking status, educational level and year of delivery [111]. Bariatric surgery was associated with a reduced risk of GDM and LGA infants, shorter gestation and an increased risk for SGA infants [111]. An increased risk of IUGR and SGA infants is consistently demonstrated also in smaller studies [112-114]. However, reduced risks of preeclampsia, GDM, hypertension, macrosomia and congenital malformations are consistently reported after bariatric surgery [114]. The effects of bariatric surgery on maternal and foetal outcomes are summarised in table 11.

The majority of the published literature come from women who have undergone RYGB. However, bariatric procedures are anatomically different and therefore differentially impact upon the rate and degree of weight loss and post-operative physiological changes. Few studies have attempted to directly compare outcomes between procedures; consequently, data are limited. Higher rates of SGA infants have been reported following biliopancreatic diversion compared to RYGB [100]. In a different study, IUGR was more common in women who underwent RYGB compared to gastric banding and sleeve gastrectomy [115]. However, a study by Facchiano et al. [116] found no significant differences in outcomes between gastric banding and RYGB in terms of obstetric complications, gestational age or birth weight. Despite sleeve gastrectomy now being the most common bariatric procedure undertaken globally, there are only few reports from pregnancies after sleeve gastrectomy $[100,117,118]$. A study comparing nutritional status in pregnancy in women after RYGB and sleeve gastrectomy showed lower rates of nutritional deficiencies following the latter [119]. Ducarme et al. [120] investigated outcomes in 63 pregnancies following sleeve gastrectomy and showed that adverse outcomes after surgery were higher in women who remained obese following surgery. Although paucity of data with regard to outcomes after sleeve gastrectomy persists, the available data suggests favourable outcomes [91, 96, 100,117, 118].

\section{Management of Pregnancy after Bariatric Surgery}

In summary, women with pregnancies who had undergone bariatric surgery represent a unique obstetric population. Current data suggests that pregnancy after bariatric surgery is safe, although good antenatal care is essential. Larger studies are required with longer 
Busetto et al.: Practical Recommendations of the Obesity Management Task Force of the European Association for the Study of Obesity for the Post-Bariatric Surgery Medical Management

follow-up of both mothers and their offspring, continuing into adulthood, to determine long-term outcomes as well as to illustrate how different bariatric procedures impact upon reproductive outcomes. The next section summarises the advice from current guidelines regarding the timing and management of pregnancy following bariatric surgery $[5,6,101$, $102,121]$.

Contraception Following Bariatric Surgery: Contraception and plans for pregnancy following bariatric surgery should be discussed early and form part of pre-operative counselling and education. In particular, women should be informed that their fertility is likely to increase immediately after surgery, and contraception should hence be discussed and offered $[5,102]$. This is of particular importance in adolescents after bariatric surgery, where rates of unwanted pregnancy are higher than both in the general adolescent population and in the total post-bariatric surgery population [122]. The choice of the contraceptive method has however been subject of debate, due to concerns about effectiveness, absorption and risks associated with hormonal contraception following bariatric surgery (see also 'Pharmacotherapy after Bariatric Surgery' above). Pharmacokinetics of hormonal contraception is differentially affected by different bariatric procedures, as oestrogen is absorbed in the upper gastrointestinal tract, which is modified during bariatric surgery [123]. Oestradiol absorption may be reduced in women following jejuno-ileal bypass and biliopancreatic diversion [86, 124]. Oral preparations of hormonal contraception should hence be avoided following biliopancreatic diversion and RYGB [125]. However, no definitive contraindication to the use has been suggested following gastric banding or sleeve gastrectomy $[125,126]$. A study measuring etonogestrel implant effectiveness following RYGB showed that hormone levels remained above the threshold required to achieve contraception in a study of three patients [127]. In a separate study, levonogestel-releasing intra-uterine devices were deemed an acceptable form of contraception in adolescents following bariatric surgery [128]. Hence, parenteral forms of hormonal contraception should be recommended first line [127]. Additional decisions regarding the contraceptive choice should be made on an individualised basis, considering procedure type, age and medical history.

Timing of Pregnancy: Nutritional deficiencies are more common in the first 12-18 months after surgery when maximal weight loss occurs [5]. A higher incidence of stillbirths has been reported when pregnancy occurs in the 1st year after surgery [100]. Furthermore, obstetric complications after bariatric surgery are more frequent at higher BMI [120]. Pregnancy is hence not recommended during 12-18 months following surgery $[6,101]$.

Pre-Conception Care: In preparation for pregnancy, women should take an additional 400 $\mu \mathrm{g}$ of folic acid in the pre-conception period, and women with a BMI that remains in the obese range or with type 2 diabetes should take $5 \mathrm{mg}$ /day until the 12th week of pregnancy [121]. In addition, women should be advised to avoid multivitamins containing vitamin $A$ in the retinol form [121].

Ante-Natal Care: Although published data state that pregnancy after bariatric surgery is safe, good ante-natal care is of vital importance due to the risk of nutritional deficiencies and the need for additional monitoring during pregnancy. Ante-natal care should be offered at a specialist centre with experience in pregnancy following bariatric surgery, via a specialist multidisciplinary ante-natal care team. Where this is not possible due to geographic restriction, liaison advice should be offered via a specialist centre.

Nutritional Supplementation and Monitoring of Nutritional Markers during Pregnancy: Adequate nutritional supplementation is required during pregnancy, in order to ensure that the nutritional needs of the mother and the growing foetus are met and to prevent nutritional deficiencies [5, 6]. In the absence of nutrient supplementation, women are at risk of iron, folate, vitamin B12 and soluble vitamin deficiencies. Reports in the literature have highlighted adverse pregnancy outcomes in the absence of adequate supplementation, including 
Busetto et al.: Practical Recommendations of the Obesity Management Task Force of the European Association for the Study of Obesity for the Post-Bariatric Surgery

Medical Management

Table 12. Recommended nutritional screening and supplementation during pregnancy $[6,104,121]$

\begin{tabular}{|c|c|c|}
\hline $\begin{array}{l}\text { Micronutritional } \\
\text { marker }\end{array}$ & $\begin{array}{l}\text { Laboratory testing } \\
\text { (each trimester) }\end{array}$ & Dose for supplementation \\
\hline Vitamin B1 & serum B1 levels & $\begin{array}{l}\text { prenatal multivitamins } \\
\text { (preparations may vary by country) }\end{array}$ \\
\hline Vitamin $\mathrm{K}$ & serum vitamin $\mathrm{K}$ & $\begin{array}{l}\text { prenatal multivitamins } \\
\text { (preparations may vary by country) }\end{array}$ \\
\hline Vitamin A & serum vitamin $\mathrm{A}$ & $\begin{array}{l}\text { prenatal multivitamins } \\
\text { (preparations may vary by country) }\end{array}$ \\
\hline Zinc & serum zinc levels & $\begin{array}{l}\text { prenatal multivitamins } \\
\text { (preparations may vary by country) }\end{array}$ \\
\hline Vitamin D & serum 25-hydroxy vitamin D & $\begin{array}{l}\text { cholecalciferol 1,000 IU daily (higher doses } \\
\text { may be required in deficient states) }\end{array}$ \\
\hline Folate & serum folate & $\begin{array}{l}400 \mu \mathrm{g} \text { or } 5 \mathrm{mg} \text { if type } 2 \text { diabetes or BMI }>30 \\
\text { until } 12 \text { th week }\end{array}$ \\
\hline Iron & $\begin{array}{l}\text { full blood count, serum ferritin, } \\
\text { serum iron and iron binding capacity }\end{array}$ & $\begin{array}{l}\text { ferrous sulphate } 200 \text { mg orally 2-3 times } \\
\text { daily }\end{array}$ \\
\hline Calcium & $\begin{array}{l}\text { serum adjusted calcium, parathyroid } \\
\text { hormone }\end{array}$ & calcium citrate $1,000-1,200 \mathrm{mg}$ \\
\hline Vitamin B12 & full blood count, Serum vitamin B12 & $1 \mathrm{mg}$ intramuscular injection every 12 weeks \\
\hline Protein & serum albumin & $60 \mathrm{~g}$ protein daily as part of balanced diet \\
\hline
\end{tabular}

maternal anaemia, neural tube defects, Wernicke's encephalopathy and foetal cerebral haemorrhage or microphthalmia [129-131]. Micronutrient supplementation is hence essential during pregnancy (table 12); these can be met with a pre-natal multivitamin preparation in addition to vitamin B12 and calcium $[6,121]$. Standard multivitamin preparations routinely used following bariatric procedures should be substituted by a pre-natal multivitamin preparation, in order to reduce vitamin A intake, which should not exceed 5,000 international U/ day [121]. A thorough nutritional assessment should be undertaken at the beginning of pregnancy [102]. This should include laboratory testing (table 12). Women who have undergone biliopancreatic diversion and duodenal switch or distal bypass procedures are at risk of soluble vitamin deficiencies [121]. Supplementation of vitamin A may be advised under specialist dietetic supervision, in the form of beta-carotene vitamin A [121]. Follow-up nutritional screening should be undertaken every trimester, and nutritional supplementation should be adjusted accordingly [121].

Ante-Natal Imaging and Growth scans: Routine ultrasounds should be performed at weeks 12 and 20. Bariatric surgery should be viewed as a risk factor for IUGR, an additional growth scan should be performed and the subsequent need for further growth surveillance should be determined at that point [102].

Screening for Gestational Complications: Screening for hypertension and GDM should be undertaken; however, consideration needs to be given to the screening modality [132]. Rapid absorption of the high glucose load used in the conventional oral glucose tolerance test 
Busetto et al.: Practical Recommendations of the Obesity Management Task Force of the European Association for the Study of Obesity for the Post-Bariatric Surgery Medical Management

(OGTT) can precipitate dumping syndrome and hypoglycaemia [102]. A $50 \mathrm{~g}$ OGTT should not be routinely used in women after bariatric surgery [91, 102]. A glycated haemoglobin level should be measured in the first trimester to exclude pre-existing diabetes, and GDM screening should be undertaken by measuring fasting and post-prandial glucose levels. Blood pressure should also be measured at every visit.

Diet during Pregnancy: Specialist dietary advice by experienced dietitians should be offered during pregnancy [102]. Active weight loss and caloric restriction are not recommended during pregnancy. Pregnant women should consume a balanced diet containing 60 g protein daily $[6,104]$. Free sugar-rich foods and beverages should be avoided as these can precipitate dumping syndrome [104]. Weight gain in pregnancy should be in line with standard recommendations for pre-pregnancy BMI [91].

Complications during Pregnancy. Women who develop gastro-intestinal symptoms during pregnancy should be thoroughly assessed, and a wide differential diagnosis list should be borne in mind, including both obstetric complications as well as surgical complications relating to their primary bariatric procedure [102]. Careful consideration should particularly be given to women presenting with abdominal pain in pregnancy [91]. RYGB results in potential internal spaces that predispose to internal herniation, which can be exacerbated by increased intra-abdominal pressure from a gravid uterus [133]. Women should be assessed by a bariatric surgeon, and diagnoses such as band slippage/erosion, herniation, small bowel obstruction and intussusception should be considered [91, 102,134]. In addition, women presenting with hyperemesis gravidarum following RYGB are at increased risk of Wernicke's encephalopathy, and treatment with parenteral vitamin B1 should be considered [5].

Birth Planning: Birth planning for women who have undergone uncomplicated bariatric surgery should follow standard guidance. Bariatric surgery in itself is not an indication for caesarean section [102].

Managing Gastric Banding in Pregnancy: No definitive advice exists regarding optimal band adjustment throughout pregnancy. Band inflation may reduce maternal complications, however this could be at the expense of foetal growth, whereas deflation may prevent bandrelated complications, but in turn could result in excessive gestational weight gain and increase risk of macrosomia and GDM [135]. Band adjustment should hence be considered on an individualised basis. Band deflation should be performed in women who present with vomiting or poor weight gain during pregnancy [136].

Managing Pregnancies when Conception Occurs within 12 Months after Surgery: Despite the advice to delay conceiving until 12-18 months after surgery, a number of women conceive during the first 12 months. However, despite the known increased risks in this group, there are no recommendations for managing these women. Importantly, women should be re-assured and encouraged to enlist a specialist ante-natal care team. Increased monitoring for nutritional deficiencies and growth scanning will be required throughout pregnancy. Dietary advice should be offered immediately post-conception, and nutritional screening should be performed. Additional growth scans should be performed at 4 -week intervals throughout the third trimester in order to closely monitor foetal growth.

Post-Partum Care: Bariatric surgery does not impact adversely upon lactation, and women should be encouraged to breastfeed. A risk of nutritional deficiencies has been suggested for infants born to mothers who have had RYGB [137]; hence nutritional supplementation and monitoring should continue during breastfeeding. 
Busetto et al.: Practical Recommendations of the Obesity Management Task Force of the European Association for the Study of Obesity for the Post-Bariatric Surgery Medical Management

Table 13. List of graded clinical practical recommendations on post-bariatric psychological aspects

\begin{tabular}{lll}
\hline Recommendations & $\begin{array}{l}\text { Level of } \\
\text { evidence }\end{array}$ & $\begin{array}{l}\text { Grade of } \\
\text { recommendation* }\end{array}$ \\
\hline $\begin{array}{l}\text { A perioperative psychological evaluation of patients prior to bariatric } \\
\text { surgery is highly recommended. Nonetheless, there may be under- } \\
\text { recognition or under-treatment of mental illness before and after } \\
\text { surgery. }\end{array}$ & 3 & $\mathrm{D}$ \\
\hline
\end{tabular}

Pre-surgical distress could worsen whenever the results of the surgery $2 \quad$ C were not meeting the patients' expectations or have not led to the hoped improvements in quality of life. Such distress might be associated with manifested depression and potentially suicidality.

Regardless of the alcohol history of the morbidly obese individual, all 2 C bariatric surgery-seeking candidates should be educated on the potential detrimental effects of this intervention, especially in the case of RYGB, in order to minimize the risk of alcohol misuse postoperatively.

The development of treatment programs focusing on both psychosocial 4 $\mathrm{D}$ factors and eating behaviours as well as weight loss is essential for a successful lifelong support.

*For the grading system refers to table 1 .

\section{Psychological Aspects}

As shown before, bariatric surgery is one of the most effective and durable treatments of morbid obesity, resulting in significant long-term weight loss as well as improvement of co-morbidities and quality of life. Consequently, it seems to be the treatment of choice for patients with severe obesity, neglecting any safety concerns. However, these concerns are reasonable since the prevalence of psychiatric co-morbidities, including suicidal ideation and/or behaviour as well as substance abuse or eating disorders, is quite high among morbidly obese individuals and bariatric surgery candidates [138]. Although a peri-operative psychological evaluation of candidates to bariatric surgery is nowadays highly recommended, there may be under-recognition or under-treatment of the mental illness before and after surgery. In this section, first-level information about psychological aspects after bariatric surgery is included, and a short list of related graded clinical practical recommendations is given in table 13 .

\section{Risk of Suicide}

Underlining psychiatric disorders may remain or recur post-operatively, resulting in an increased risk of suicide among patients who received bariatric surgery [139]. Several studies demonstrated higher suicide rates among bariatric surgery patients than among non-bariatric surgery patients or the general community. These findings are supported by Tindle et al. [140] who documented an excess of suicides post-operatively, with $30 \%$ of the suicides occurring within the first 2 years and almost 70\% occurring within 3 years after surgery. Moreover, approximately $10 \%$ of bariatric surgery candidates report a lifetime history of suicide attempts, a higher rate than in the general community [141]. For surgery-seeking 
Busetto et al.: Practical Recommendations of the Obesity Management Task Force of the European Association for the Study of Obesity for the Post-Bariatric Surgery Medical Management

women Chen et al. [141] reported that weight-related stigma was associated with suicidal ideation and/or behaviour. To further understand the mortality pattern of these patients, Omalu et al. [142] studied the role of bariatric surgery in this context. In the three studied cases, wherein suicide was committed following bariatric surgery, a recurrent major depressive disorder was present before and after the intervention, concluding that the depressive disorder must have remained although a successful surgical control of obesity was obtained. The study of Omalu et al. [142] shows how essential a psychological evaluation of the bariatric-surgery patient might be for any early evaluation of psychological problems post-operatively. Such problems might include a lack of improvement in quality of life after surgery, continued or recurrent physical mobility restrictions, persistence or recurrence of sexual dysfunction and relationship problems or a history of child maltreatment and might contribute to suicidal ideas and/or behaviour post-operatively if not assessed. Furthermore, pre-surgical psychological distress could worsen if the results of the surgery were disappointing or failed to have the hoped improvements in quality of life. Herein, one should keep in mind that morbidly obese patients might have unrealistic expectations of body appearance post-operatively and are therefore constantly disappointed by the aesthetic outcome of their surgery. Thus, inadequate weight loss or weight regain might be another cause for a passing thought of suicide. Therefore, it is essential to support these patients with psychological and/ or psychiatric treatment if needed and help them to find a new way through life.

\section{Alcohol Abuse}

Bariatric surgery not only increases the risk of suicidal ideation and/or behaviour, it also elevates the risk for an alcoholic disease. The underlying mechanism is poorly understood, but consistent research suggests that following certain forms of bariatric surgery (i.e. RYGB) the pharmacokinetic parameters of alcohol are altered and thereby may heighten the alcohol sensitivity of the individual. Besides, several anatomical or physiological changes upon surgery may also contribute to altered alcohol absorption and/or metabolism [143]. The increased risk of alcohol misuse after surgery could also be due to a shift of addictions, wherein alcohol substitutes food as coping mechanism [144]. Obviously, the pattern of alcohol use pre-operatively also play a role in this addiction transfer. Thus, it is not surprising that regular alcohol consumption pre-operatively increases the likelihood of an alcoholic disease postoperatively. Although Wee et al. [144] could show that more than half of the weight loss patients, who reported alcohol abuse before surgery, discontinued high-risk drinking, and $7 \%$ of the patients in this study reported new high-risk drinking 1 year after the intervention. Interestingly, the prevalence of alcohol misuse significantly increases in the 2nd year after surgery as demonstrated by King et al. [145]. Thus, regardless of the alcohol history of the morbidly obese individual, all bariatric surgery-seeking candidates should be educated on the potential effects of this intervention, especially in the case of RYGB, in order to minimise the risk of alcohol misuse post-operatively.

\section{Eating Behaviour Disorders}

The prevalence of compulsive eating patterns known as binge eating disorder is quite common among bariatric surgery-seeking patients. Usually this prevalence decreases significantly as soon as weight and shape concerns diminish post-operatively. However, research has shown that these problems can persist after bariatric surgery [146]. Furthermore, several studies have demonstrated that a sub-group of patients may develop 'loss of control' eating following surgery, and even self-induced vomiting due to weight and shape reasons was reported. A post-surgery-developed eating disorder is mostly associated with less weight loss and increased subjective phobia of weight regain. Obviously, a pre-surgery eating disorder also increases the likelihood of such outcomes. However, not all of the bariatric surgery- 
Busetto et al.: Practical Recommendations of the Obesity Management Task Force of the European Association for the Study of Obesity for the Post-Bariatric Surgery

Medical Management

Table 14. List of graded clinical practical recommendations on weight regain prevention and management after bariatric surgery

\begin{tabular}{lll}
\hline Recommendations & $\begin{array}{l}\text { Level of } \\
\text { evidence }\end{array}$ & $\begin{array}{l}\text { Grade of } \\
\text { recommendation* }\end{array}$ \\
\hline $\begin{array}{l}\text { Weight regain after bariatric surgery is a result of hormonal and } \\
\text { metabolic alterations, surgical failure, nutritional non-adherence, } \\
\text { mental health issues and physical inactivity. }\end{array}$ & 3 & $\mathrm{D}$ \\
\hline $\begin{array}{l}\text { Enforcing and sustaining healthy lifestyle facilitates weight regain } \\
\text { prevention. }\end{array}$ & 3 & $\mathrm{D}$ \\
\hline $\begin{array}{l}\text { Adding anti-obesity drugs and/or re-do operations may halt weight } \\
\text { regain or create further weight loss when applied at optimal timing. }\end{array}$ & 3 & $\mathrm{D}$ \\
\hline & \\
\hline
\end{tabular}

seeking patients with 'loss of control' eating pre-operatively developed an eating disorder after surgery or even showed a tendency to develop bulimia nervosa or anorexia nervosa [143]. Such a restrictive behaviour is often seen when the old eating pattern recurs. Consequently, self-induced vomiting or food avoidance is performed in an effort to prevent weight regain. Besides, also a compensatory behaviour known as post-surgical eating avoidance disorder [147] can be observed in some patients, when weight loss slows down or stops. Taken together, all of the above mentioned eating disorders have two things in common: they all demonstrate that these patients have neither adapted to their new demands in their eating behaviours after surgery nor that they have learned to cope with stress or other problems in a new way. Thus, it is imperative that treatment programmes are developed, which address the special needs of this patient group, focusing on both psycho-social factors and eating behaviours as well as on weight loss for a successful support.

\section{Weight Regain Prevention and Management}

Weight regain after bariatric surgery is a result of hormonal and metabolic alterations, surgical failure, nutritional non-adherence, mental health issues and physical inactivity [148]. Although randomised controlled trials specifically targeting prevention of weight regain are lacking, current observations suggest that enforcing and sustaining healthy lifestyle facilitates adherence to therapy and therefore helps to prevent weight regain. Adding anti-obesity drugs and/or re-do operations may halt weight regain or create further weight loss when applied at optimal timing. In this last section, first-level information about weight regain prevention and management is included, and a short list of related graded clinical practical recommendations is given in table 14 .

Although the exact aetiology of weight regain is not well understood, it is clearly multifactorial. Aside from lifestyle issues, genetic background and time from surgery are all risk factors. In addition, decreased satiety can occur because of variety of reasons, e.g. as a result of dilation of the gastro-jejunal stoma (the connection between the gastric pouch and jejunum) in RYGB or of volume dilatation of the reduced stomach, pointing to an interplay between behavioural factors and post-operative body compensatory mechanisms influencing anatomy [149]. After any bariatric and/or metabolic procedure, it is quite natural 
Busetto et al.: Practical Recommendations of the Obesity Management Task Force of the European Association for the Study of Obesity for the Post-Bariatric Surgery Medical Management

that some weight regain occurs in long-term follow-up. It is estimated that around $50 \%$ of post-bariatric patients regain around $5 \%$ of their body weight in 2 years after the procedure [150].

There are several success components contributing to desirable and adequate outcomes of the surgical treatment of obesity. Standardised, life-long follow-up available and provided to all the post-bariatric patients is among the most important ones. Decades of bariatric surgery have proven that treatment outcomes and success after bariatric surgery is dependent on technically perfect surgery. However, success depends more significantly on patient longterm compliance with a follow-up regimen. Patients who are compliant with the follow-up requirements and attend the support groups programmes, including education about dietary requirements, exhibit better and enhanced outcomes (approximately 10\% lower BMI) in comparison with those who did not attend any of the follow-up programmes [151]. An important part of the follow-up regimen is that the follow-up team is composed by multidisciplinary experts. Thus, the team of experts ideally comprise a nutritionist/dietician, a psychologist, a specialised physician and a bariatric surgeon $[152,153]$. The follow-up interventions of both the support groups as well as the team of experts are focused, among other tasks, on leveraging lifestyle changes and affording the patient to commit to those changes and to maintain them in the long run [151].

An important component of successful and long-lasting weight loss is adherence to nutrient-dense foods, containing sufficient amounts of lean proteins and fibres (fruits and vegetables). This is especially true in longer term after bariatric surgery when the stomach volume slowly, however inevitably, expands and appetite begins to increase. High-volume foods like vegetables and fruits can contribute substantially to weight regain prevention $[6$, 154].

Patients attending support groups after bariatric/metabolic surgery show enhanced weight loss and other treatment outcomes, specifically after RYGB and adjustable gastric banding. Patients should be repeatedly educated about staged meal progression dependent on the time elapsed after surgery and based on the type of surgical procedure they underwent. Patients should also be informed that an excessive number and size of meals would probably result in lower weight loss $[7,151,155,156]$. A consultation for post-operative meal initiation and progression should be arranged with a dietician who is knowledgeable of the post-operative bariatric diet. Patients should receive education in a protocol-derived staged meal progression based on their surgical procedure. Patients should be counselled to eat three small meals during the day and chew small bites of food thoroughly before swallowing. Patients should adhere with principles of healthy eating, including at least five daily servings of fresh fruits and vegetables $[7,155,156]$.

Fitness and adequate, slowly increasing physical activity contributes to preserving and building muscle mass. This further contributes to successful weight loss and prevents weight regain. Patients should be advised to incorporate moderate aerobic physical activity, i.e., a minimum of $150 \mathrm{~min} /$ week (with a goal of $300 \mathrm{~min} /$ week) as well as strength training 2-3 times per week. Walking with the aim for small, attainable increases in walking distances could be the optimal exercise modality, at least for several months after operation. Losing some weight prior to the procedure may further contribute to more pronounced weight loss after bariatric surgery and increases the likelihood of long-term weight maintenance following the operation [2].

In the European Guidelines for Obesity Management in Adults [2] and in the Interdisciplinary European Guidelines on Metabolic and Bariatric Surgery [157] it has been highlighted that the interdisciplinary teams are ideally available in specialised clinics like European Association for the Study of Obesity Collaborating Centres for Obesity Management (EASO-COMs). The team members should be responsible for follow-up; however, the ultimate responsibility 
Busetto et al.: Practical Recommendations of the Obesity Management Task Force of the European Association for the Study of Obesity for the Post-Bariatric Surgery

Medical Management

should remain with the physician and surgeon who were engaged in the pre-operative and operation period.

As it was already mentioned, there are several important rules that should be respected in order to optimise bariatric surgery outcomes after different types of operations. The rules are stated in the Interdisciplinary European Guidelines on Metabolic and Bariatric Surgery [151]. In general, it has to be stressed that a better understanding of substantial metabolic changes induced by different surgical interventions to the alimentary tract was achieved in the past several years. Therefore, the former classification of operations according to their influence on food ingestion, defined as limiting stomach capacity (restrictive), limiting absorption of nutrients (malabsorptive) or combined procedures does not appropriately reflect the current level of knowledge about early and weight-independent metabolic effects of these operations. Nowadays, most of the standard surgical interventions are being mostly referred to as metabolic operations. The focus when treating obese patients is gradually shifting from the primary goal of weight loss outcomes to the metabolic effects of the operations. However for didactical reasons, the former classification is still used [151].

Follow-up during the 1st year should be at least every 3 months, starting 1 month post-operatively until a clinically satisfactory rate of weight loss is achieved. Thereafter, follow-up should be done annually. Follow-up should be carried out by the interdisciplinary team and include dietary change / behavioural modification / physical activity interventions and encouragement as well as pharmacology support and surgical revision if appropriate [151].

In general, anti-obesity drugs may contribute to weight loss in patients with obesity [158]. After bariatric surgery, anti-obesity drugs are usually started when weight regain ensues. Prescribing weight loss pharmacotherapy before weight regain occurs (at weight plateau) may result in greater amount of total weight loss from the pre-operative period [159] and may prevent weight regain. A recent retrospective review demonstrated that phentermine alone and a phentermine-topiramate combination, in addition to diet and exercise, appear to be viable options for weight loss in RYGB and adjustable gastric banding patients who experienced weight recidivism or weight loss plateau [160]. Another study showed that medical treatment directed to the control of satiety using liraglutide may be an alternative treatment of patients with poor weight loss or weight regain after surgery [161]. Since most of the studies reporting the utility of anti-obesity drugs are retrospective and such clinical studies at present are of small scale, further prospective randomised clinical trials should be performed to demonstrate the effect of drugs on prevention and treatment of weight regain.

It may be expected that in the long term a certain weight regain occurs after most of the bariatric operations. Such weight regain is to be viewed as a result of progression of the chronic disease of obesity and should not be considered as failure of the surgical treatment. Thus, the true failure of the surgical treatment results in surgical emergency and necessitates emergency re-operation. On the contrary, elective redo surgery offers the opportunity to further leverage surgical treatment and to re-adjust it according to disease development and progression. The choice of redo operation depends on surgeon's opinion and institutional standardised algorithm. Patient's satisfaction and compliance with the previous surgery and patient's individual preferences should also be taken into account. In general, the type of redo surgery should be chosen in line with a complex analysis of causes of weight regain, an interdisciplinary assessment of a given patient and the patient's preference. 
Busetto et al.: Practical Recommendations of the Obesity Management Task Force of the European Association for the Study of Obesity for the Post-Bariatric Surgery Medical Management

\section{Conclusion}

Bariatric surgery today is the most effective long-term therapy for the management of patients with severe and/or complicated obesity. This simple observation, now incorporated in the most relevant guidelines of the management of obesity in adults [2], leads to a gradual but continuous increase in the number of bariatric procedures performed in Europe and world-wide [1]. Bariatric surgery is in general safe and effective, but it can cause new clinical problems and it is associated with specific diagnostic, preventive and therapeutic needs. Special knowledge and skills of the clinicians are required in order to deliver appropriate and effective care to the post-bariatric patient. A post-bariatric multidisciplinary follow-up programme should be an integral part of the clinical pathway at centres delivering bariatric surgery, and it should be offered to patients requiring it [151]. However, giving the growing number of post-bariatric patients, an increasing part of the follow-up, particularly after the early period after surgery, should also be transferred to the primary care physicians and to obesity specialists, dieticians and nurses not primarily engaged in the bariatric programme.

\section{Acknowledgements}

This document has been written by a group of obesity experts gathered by the Obesity Management Task Force of the European Association for the Study of Obesity. Luca Busetto and Dror Dicker coordinated the group and contributed equally to the preparation of the final paper.

\section{Disclosure Statement}

None of the authors declared substantial conflict of interests in relation to the contents of these paper.

\section{References}

1 Sjöström L: Review of the key results from the Swedish Obese Subjects (SOS) trial - a prospective controlled intervention study of bariatric surgery. J Intern Med 2013;273:219-234.

2 Yumuk V, Tsigos C, Fried M, Schindler K, Busetto L, Micic D, Toplak H; Obesity Management Task Force of the European Association for the Study of Obesity: European guidelines for obesity management in adults. Obes Facts 2015;8:402-424.

3 Angrisani L, Santonicola A, Iovino P, Formisano G, Buchwald H, Scopinaro N: Bariatric surgery worldwide 2013. Obes Surg 2015;25:1822-1832.

4 Mechanick JI, Kushner RF, Sugerman HJ, Gonzalez-Campoy JM, Collazo-Clavell ML, Guven S, Spitz AF, Apovian CM, Livingston EH, Brolin R, Sarwer DB, Anderson WA, Dixon J; American Association of Clinical Endocrinologists, The Obesity Society, American Society for Metabolic \& Bariatric Surgery: Medical guidelines for clinical practice for the perioperative nutritional, metabolic, and nonsurgical support of the bariatric surgery patient. Endocr Pract 2008;14(suppl 1):1-83.

5 Aills L, Blankenship J, Buffington C, Furtado M, Parrott J; Allied Health Sciences Section Ad Hoc Nutrition Committee:ASMBS Allied Health Nutritional Guidelines for the Surgical Weight Loss Patient. Surg Obes Related Dis 2008;4(suppl):S73-S108.

6 Mechanick JI, Youdim A, Jones DB, Garvey WT, Hurley DL, McMahon MM, Heinberg LJ, Kushner R, Adams TD, Shikora S, Dixon JB, Brethauer S: Clinical practice guidelines for the perioperative nutritional, metabolic, and nonsurgical support of the bariatric surgery patient-2013 update: cosponsored by American Association of Clinical Endocrinologists, The Obesity Society, and American Society for Metabolic \& Bariatric Surgery. Obesity (Silver Spring) 2013;21(suppl 1):S1-S27.

7 Sarwer DB, Moore RH, Spitzer JC, Wadden TA, Raper SE, Williams NN. A pilot study investigating the efficacy of postoperative dietary counseling to improve outcomes after bariatric surgery. Surg Obes Relat Dis 2012;8: 561-568.

8 Jacobi D, Ciangura C, Couet C, Oppert JM: Physical activity and weight loss following bariatric surgery. Obes Rev 2011;12:366-377. 
Busetto et al.: Practical Recommendations of the Obesity Management Task Force of the European Association for the Study of Obesity for the Post-Bariatric Surgery Medical Management

9 Bavaresco M, Paganini S, Pereira Lima T, Salgado W Jr, Ceneviva R, Dos Santos JE, Nonino-Borges CB: Nutritional course of patients submitted to bariatric surgery. Obes Surg 2010;20:716-721.

10 Brolin RE, LaMarca LB, Kenler HA, Cody RP: Malabsorptive gastric bypass in patients with superobesity. J Gastrointest Surg 2002;6:195-203.

11 Faintuch J, Matsuda M, Cruz ME, Silva MM, Teivelis MP, Garrido AB Jr, Gama-Rodrigues JJ: Severe protein calorie malnutrition after bariatric procedures. Obes Surg 2004;14:175-181.

12 Byrne TK: Complications of surgery for obesity. Surg Clin North Am 2001;81:1181-1193.

13 Potoczna N, Harfmann S, Steffen R, Briggs R, Bieri N, Horber FF: Bowel habits after bariatric surgery. Obes Surg 2008;18:1287-1296.

14 Sigstad H: A clinical diagnostic index in the diagnosis of the dumping syndrome. Changes in plasma volume and blood sugar after a test meal. Acta Med Scand 1970;188:479-486.

15 Papamargaritis D, Koukoulis G, Sioka E, Zachari E, Bargiota A, Zacharoulis D, Tzovaras G: Dumping symptoms and incidence of hypoglycaemia after provocation test at 6 and 12 months after laparoscopic sleeve gastrectomy. Obes Surg 2012;22:1600-1606.

16 Laurenius A, Olbers T, Näslund I, Karlsson J: Dumping syndrome following gastric bypass: validation of the Dumping Symptom Rating Scale. Obes Surg 2013;23:740-755.

17 Banerjee A, Ding Y, Mikami DJ, Needleman BJ: The role of dumping syndrome in weight loss after gastric bypass surgery. Surg Endosc 2013;27:1573-1578.

18 Tack J, Arts J, Caenepeel P, De Wulf D, Bisschops R: Pathophysiology, diagnosis and management of postoperative dumping syndrome. Nat Rev Gastroenterol Hepatol 2009;6:583-590.

19 Yamamoto H, Mori T, Tsuchihashi H, Akabori H, Naito H, Tani T: A possible role of GLP-1 in the pathophysiology of early dumping syndrome. Dig Dis Sci 2005;50:2263-2267.

20 Deitel M: The change in the dumping syndrome concept. Obes Surg 2008;18:1622-1624.

21 Patti ME, Goldfine AB: Hypoglycemia after gastric bypass: the dark side of GLP-1. Gastroenterology 2014;146: 605-608.

22 Nannipieri M, Belligoli A, Guarino D, Busetto L, Moriconi D, Fabris R, Mari A, Baldi S, Anselmino M, Foletto M, Vettor R, Ferrannini E: Risk factors for spontaneously self-reported postprandial hypoglycemia after bariatric surgery. J Clin Endocrinol Metab 2016;101:3600-3607.

23 Ukleja A: Dumping syndrome: pathophysiology and treatment. Nutr Clin Pract 2005;20:517-525.

24 Ceppa EP, Ceppa DP, Omotosho PA, Dickerson JA 2nd, Park CW, Portenier DD: Algorithm to diagnose etiology of hypoglycemia after Roux-en-Y gastric bypass for morbid obesity: case series and review of the literature. Surg Obes Relat Dis 2012;8:641-647.

25 Parrott J, Frank L, Rabena R, Craggs-Dino L, Isom KA, Greiman L: American Society for Metabolic and Bariatric Surgery integrated health nutritional guidelines for the surgical weight loss patient 2016 Update: micronutrients. Surg Obes Relat Dis 2017;13:727-741.

26 Damms-Machado A, Friedrich A, Kramer KM, Stingel k, Meile T, Küper MA, Königsrainer A, Bischoff S: Pre- and postoperative nutritional deficiencies in obese patients undergoing laparoscopic sleeve gastrectomy. Obes Surg 2012;22:881-889.

27 Slater GH, Ren CJ, Seigel N, Williams T, Barr D, Wolfe B, Dolan K, Fielding GA: Serum fat-soluble vitamin deficiency and abnormal calcium metabolism after malabsorptive bariatric surgery. J Gastrointest Surg 2004;8: 48-55.

28 Newbury L, Dolan K, Hatzifotis M, Fielding G: Calcium and vitamin D depletion and elevated parathyroid hormone following biliopancreatic diversion. Obes Surg 2003;13:893-895.

29 Johnson JM, Maher JW, DeMaria EJ, Downs RW, Wolfe LG, Kellum JM: The long term effects of gastric bypass on vitamin D metabolism. Ann Surg 2006;243:701-704.

30 Luger M, Kruschitz R, Langer F, Prager G, Walker M, Marculescu R, Hoppichler F, Schindler K, Ludvik B: Effects of omega-loop gastric bypass on vitamin $\mathrm{D}$ and bone metabolism in morbidly obese bariatric patients. Obes Surg 2015;25:1056-1062.

31 Giusti V, Gasteyger C, Suter M, Heraief E, Galliard RC, Burckhardt P: Gastric banding induces negative bone remodeling in the absence of secondary hyperparathyroidism: potential of serum telopeptides for follow-up. Int J Obes 2005;29:1429-1435.

32 Loh Y, Watson WD, Verma A, Chang ST, Stocker DJ, Labutta RJ: Acute Wernicke's encephalopathy following bariatric surgery: clinical course and MRI correlation. Obes Surg 2004;14:129-132.

33 Bozboa A, Coskun H, Ozarmagan S, Erbil Y, Ozbey N, Orham Y: A rare complication of adjustable gastric banding: Wernicke's encephalopathy. Obes Surg 2000;19:274-275.

34 Makarewicz W, Kaska L, Kobiela J, Stefaniak T, Krajewski J, Stankiewicz M, Wujtewicz MA, Lachinski AJ, Sledzinski Z: Wernicke's syndrome after sleeve gastrectomy. Obes Surg 2007;17:704-706.

35 Primavera A, Brusa G, Novello P, Schenone A, Gianetta E, Marinari G, Cuneo S, Scopinaro N: Wernicke-Korsakoff encephalopathy following biliopancreatic diversion. Obes Surg 1998;3:175-177.

36 Boateng AA, Sriram K, Meguid MM, Crook M: Refeeding syndrome: treatment considerations based on collective analysis of literature case reports. Nutrition 2010;26:156-167.

37 Olivares M, Pizarro F, Ruz M, de Romaña DL: Acute inhibition of iron bioavailability by zinc: studies in humans. Biometals 2012;25:657-664.

38 Troost FJ, Brummer RJ, Dainty JR, Hoogewerff JA, Bull VJ, Saris WH: Iron supplements inhibit zinc but not copper absorption in vivo in ileostomy subjects. Am J Clin Nutr 2003;78:1018-1023. 
Busetto et al.: Practical Recommendations of the Obesity Management Task Force of the European Association for the Study of Obesity for the Post-Bariatric Surgery Medical Management

39 Busetto L: Post-bariatric surgery nutrition; in Rios B (ed): Integrated Health in Bariatric Surgery. Mexico City, Instituto de Investigación y Educación en Ciencias de la Salud (IIECS), 2015.

40 Welbourn R, Dixon J, Higa K: Second IFSO Global Registry Report 2016. www.ulusalobeziteveritabani.com/ wp-content/uploads/2016/11/2nd-ifso-report.pdf (last accessed November 22, 2107).

41 Buchwald H Avidor Y, Braunwald E, Jensen MD, Pories W, Fahrbach K, Schoelles K: Bariatric surgery: a systematic review and meta-analysis. JAMA 2004;292:1724-1737.

42 Iaconelli A, Panunzi S, De Gaetano A, Manco M, Guidone C, Leccesi L, Gniuli D, Nanni G, Castagneto M, Ghirlanda G, Mingrone G: Effects of bilio-pancreatic diversion on diabetic complications: a 10-year follow-up. Diabetes Care 2011;34:561-567.

43 Adams TD, Gress RE, Smith SC, Halverson RC, Simper SC, Rosamond WD, Lamonte MJ, Stroup AM, Hunt SC: Long-term mortality after gastric bypass surgery. N Engl J Med 2007;357:753-761.

44 Dicker D, Yahalom R, Comaneshter DS, Vinker S: Long-term outcomes of three types of bariatric surgery on obesity and type 2 diabetes control and remission. Obes Surg 2016;26:1814-1820.

45 Perna M, Romagnuolo J, Morgan K, Byrne TK, Baker M: Preoperative hemoglobin A1c and postoperative glucose control in outcomes after gastric bypass for obesity. Surg Obes Relat Dis 2012;8:685-690.

46 Royal Cornwall Hospital: Clinical Guideline for the Management of an Adult with Type 2 Diabetes Pre and Post Bariatric Surgery. www.rcht.nhs.uk/DocumentsLibrary/RoyalCornwallHospitalsTrust/Clinical/GeneralSurgery/ProtocolForTheManagementOfPatientsWithTypeTwoDia.pdf (last accessed November 22, 2107).

47 Rometo D, Korytkowski M: Perioperative glycemic management of patients undergoing bariatric surgery. Curr Diab Rep 2016;16:23.

48 Machnica K, Pannain S, Schulwolf E: Inpatient glycemic protocol for patients with diabetes undergoing bariatric sSurgery. Obes Surg 2015;25:2200-2204.

49 Buse JB, Caprio S, Cefalu WT, Ceriello A, Del Prato S, Inzucchi SE, McLaughlin S, Phillips GL 2nd, Robertson RP, Rubino F, Kahn R, Kirkman MS: How do we define cure of diabetes? Diabetes Care 2009;32:2133-2135.

50 Jonas DE, Amick HR, Feltner C, Weber RP, Arvanitis M, Stine A, Lux L, Harris RP: Screening for obstructive sleep apnea in adults: evidence report and systematic review for the US Preventive Services Task Force. JAMA 2017; 317:415-433.

51 Javaheri S, Barbe F, Campos-Rodriguez F, Dempsey JA, Khayat R, Javaheri S, Malhotra A, Martinez-Garcia MA, Mehra R, Pack AI, Polotsky VY, Redline S, Somers VK: Sleep apnea: types, mechanisms, and clinical cardiovascular consequences. J Am Coll Cardiol 2017;69:841-858.

52 Reutrakul S, Van Cauter E: Interactions between sleep, circadian function, and glucose metabolism: implications for risk and severity of diabetes. Ann N Y Acad Sci 2014;1311:151-173.

53 Fredheim JM, Rollheim J, Omland T, Hofsø D, Røislien J, Vegsgaard KM, Hjelmesæth J: Type 2 diabetes and prediabetes are associated with obstructive sleep apnea in extremely obese subjects. Cardiovasc Diabetol 2011;10:84.

54 Fredheim JM, Røislien J, Hjelmesæth J: Validation of a portable monitor for the diagnosis of obstructive sleep apnea in morbidly obese patients. J Clin Sleep Med 2014;10:751-757.

55 Ravesloot MJ, van Maanen JP, Hilgevoord AA, van Wagensveld BA, de Vries N: Obstructive sleep apnea is underrecognized and underdiagnosed in patients undergoing bariatric surgery. Eur Arch Otorhinolaryngol 2012;269:1865-1871.

56 de Raaff CA, Pierik AS, Coblijn UK, de Vries N, Bonjer HJ, van Wagensveld BA: Value of routine polysomnography in bariatric surgery. Surg Endosc 2017;31:245-248.

57 Kuklisova Z, Tkacova R, Joppa P, Wouters E, Sastry M: Severity of nocturnal hypoxia and daytime hypercapnia predicts CPAP failure in patients with COPD and obstructive sleep apnea overlap syndrome. Sleep Med 2017; 30:139-145.

58 Carlucci A, Ceriana P, Mancini M, Cirio S, Pierucci P, D’Artavilla Lupo N, Gadaleta F, Morrone E, Fanfulla F: Efficacy of bilevel-auto treatment in patients with obstructive sleep apnea not responsive to or intolerant of continuous positive airway pressure ventilation. J Clin Sleep Med 2015;11:981-985.

59 Ashrafian H, Toma T, Rowland SP, Harling L, Tan A, Efthimiou E, Darzi A, Athanasiou T: Bariatric surgery or non-surgical weight loss for obstructive sleep apnoea? A systematic review and comparison of meta-analyses. Obes Surg 2015;25:1239-1250.

60 de Raaff CA, Coblijn UK, Ravesloot MJ, de Vries N, de Lange-de Klerk ES, van Wagensveld BA: Persistent moderate or severe obstructive sleep apnea after laparoscopic Roux-en-Y gastric bypass: which patients? Surg Obes Relat Dis 2016;12:1866-1872.

61 O'Kane M, Parretti HM, Hughes CA, Sharma M, Woodcock S, Puplampu T, Blakemore AI, Clare K, MacMillan I, Joyce J, Sethi S, Barth JH: Guidelines for the follow-up of patients undergoing bariatric surgery. Clin Obes 2016; 6:210-224.

62 Alberti KG, Eckel RH, Grundy SM, Zimmet PZ, Cleeman JI, Donato KA, Fruchart JC, James WP, Loria CM, Smith SC Jr: Harmonizing the metabolic syndrome: a joint interim statement of the International Diabetes Federation Task Force on Epidemiology and Prevention, National Heart, Lung, and Blood Institute, American Heart Association, World Heart Federation, International Atherosclerosis Society and International Association for the Study of Obesity. Circulation 2009;120:1640-1645.

63 Valderhaug TG, Aasheim ET, Sandbu R, Jakobsen GS, Småstuen MC, Hertel JK, Hjelmesæth J: The association between severity of King's Obesity Staging Criteria scores and treatment choice in patients with morbid obesity: a retrospective cohort study. BMC Obes 2016;3:51. 
Busetto et al.: Practical Recommendations of the Obesity Management Task Force of the European Association for the Study of Obesity for the Post-Bariatric Surgery Medical Management

64 Catapano AL, Graham I, De Backer G, Wiklund O, Chapman MJ, Drexel H, Hoes AW, Jennings CS, Landmesser U, Pedersen TR, Reiner Ž, Riccardi G, Taskinen MR, Tokgozoglu L, Verschuren WM, Vlachopoulos C, Wood DA, Zamorano JL: 2016 ESC/EAS guidelines for the management of dyslipidaemias. Eur Heart J 2016;37:29993058.

65 Garvey WT, Mechanick JI, Brett EM, Garber AJ, Hurley DL, Jastreboff AM, Nadolsky K, Pessah-Pollack R, Plodkowski R: American Association of Clinical Endocrinologists and American College of Endocrinology comprehensive clinical practice guidelines for medical care of patients with obesity. Endocr Pract 2016;22(suppl 3):1-203.

66 Bays HE, Jones PH, Jacobson TA, Cohen DE, Orringer CE, Kothari S, Azagury DE, Morton J, Nguyen NT, Westman EC, Horn DB, Scinta W, Primack C: Lipids and bariatric procedures part 1 of 2: scientific statement from the National Lipid Association, American Society for Metabolic and Bariatric Surgery, and Obesity Medicine Association: J Clin Lipidol 2016;10:33-57.

67 Bays HE, Kothari SN, Azagury DE, Morton JM, Nguyen NT, Jones PH, Jacobson TA, Cohen DE, Orringer C, Westman EC, Horn DB, Scinta W, Primack C: Lipids and bariatric procedures part 2 of 2: scientific statement from the American Society for Metabolic and Bariatric Surgery (ASMBS), the National Lipid Association (NLA), and Obesity Medicine Association (OMA). Surg Obes Relat Dis 2016;12:468-495.

68 Pihlajamäki J, Grönlund S, Simonen M, Käkelä P, Moilanen L, Pääkkönen M, Pirinen E, Kolehmainen M, Kärjä V, Kainulainen S, Uusitupa M, Alhava E, MiettinenTA, Gylling H: Cholesterol absorption decreases after Rouxen-Y gastric bypass but not after gastric banding. Metabolism 2010;59:866-872.

69 De Vuono S, Ricci MA, Siepi D, Boni M, Gentili A, Scavizzi M, Daviddi G, Labate P, Roscini AR, Lupattelli G: Laparoscopic sleeve gastrectomy modifies cholesterol synthesis but not cholesterol absorption. Obes Res Clin Pract 2017;11:118-122.

70 Heffron SP, Parikh A, Volodarskiy A, Ren-Fielding C, Schwartzbard A, Nicholson J, Bangalore S: Changes in lipid profile of obese patients following contemporary bariatric surgery: a meta-analysis. Am J Med 2016;129: 952-959.

71 Carswell KA, Belgaumkar AP, Amiel SA, Patel AG: A Systematic review and meta-analysis of the effect of gastric bypass surgery on plasma lipid levels. Obes Surg 2016;26:843-855.

72 Johnson LK, Andersen LF, Hofsø D, Aasheim ET, Holven KB, Sandbu R, Røislien J, Hjelmesæth J: Dietary changes in obese patients undergoing gastric bypass or lifestyle intervention: a clinical trial. Br J Nutr 2013;110:127134.

73 Risstad H, Svanevik M, Kristinsson JA, Hjelmesæth J, Aasheim ET, Hofsø D, Søvik TT, Karlsen TI, Fagerland MW, Sandbu R, Mala T: Standard vs distal Roux-en-Y gastric bypass in patients with body mass index 50 to 60:a double-blind, randomized clinical trial. JAMA Surg 2016;151:1146-1155.

74 Gloy VL, Briel M, Bhatt DL, Kashyap SR, Schauer PR, Mingrone G, Bucher HC, Nordmann AJ: Bariatric surgery versus non-surgical treatment for obesity: a systematic review and meta-analysis of randomised controlled trials. BMJ 2013;347:f5934.

75 Schauer PR, Kashyap SR, Wolski K, Brethauer SA, Kirwan JP, Pothier CE, Thomas S, Abood B, Nissen SE, Bhatt DL: Bariatric surgery versus intensive medical therapy in obese patients with diabetes. N Engl J Med 2012; 366:1567-1576.

76 Yska JP, van der Linde S, Tapper VV, Apers JA, Emous M, Totté ER, Wilffert B, van Roon EN: Influence of bariatric surgery on the use and pharmacokinetics of some major drug classes. Obes Surg 2013;23:819-825.

77 Jakobsen GS, Skottheim IB, Sandbu R, Christensen H, Røislien J, Asberg A, Hjelmesæth J: Long-term effects of gastric bypass and duodenal switch on systemic exposure of atorvastatin. Surg Endosc 2013;27:2094-2101.

78 Jordan J, Yumuk V, Schlaich M, Nilsson PM, Zahorska-Markiewicz B, Grassi G, Schmieder RE, Engeli S, Finer N: Joint statement of the European Association for the Study of Obesity and the European Society of Hypertension: obesity and difficult to treat arterial hypertension. J Hypertens 2012;30:1047-1055.

79 Azran C, Wolk O, Zur M, Fine-Shamir N, Shaked G, Czeiger D, Sebbag G, Kister O, Langguth P, Dahan. Oral drug therapy following bariatric surgery: an overview of fundamentals, literature and clinical recommendations. Obes Rev 2016;17:1050-1066.

80 Silverman J, Catella J, Tavakkolizadeh A, Robinson M, Churchill W: Bariatric surgery pharmacy consultation service. Obes Surg 2011;21:1477-1481.

81 Padwal R, Brocks D, Sharma AM: A systematic review of drug absorption following bariatric surgery and its theoretical implications. Obes Rev 2010;11:41-50.

82 Padwal RS, Gabr RQ, Sharma AM, Langkaas LA, Birch DW, Karmali S, Brocks DR: Effect of gastric bypass surgery on the absorption and bioavailability of metformin. Diabetes Care 2011;34:1295-1300.

83 Hallersund P, Sjöström L, Olbers T, Lönroth H, Jacobson P, Wallenius V, Näslund I, Carlsson LM, Fändriks L: Gastric bypass surgery is followed by lowered blood pressure and increased diuresis - long term results from the Swedish Obese Subjects (SOS) study. PLoS One 2012; 7:e49696.

84 Felix E, Kettelle J, Mobley E, Swartz D: Perforated marginal ulcers after laparoscopic gastric bypass. Surgl Endosc 2008;22:2128-2132.

85 Sasse K, Ganser J, Kozar M, Watson RW, McGinley L, Lim D, Weede M, Smith CJ, Bovee V: Seven cases of gastric perforation in Roux-en-Y gastric bypass patients: what lessons can we learn? Obes Surg 2008;18:530-534.

86 Gerrits E, Ceulemans R, van Hee R, Hendrickx L, Totté E: Contraceptive treatment after biliopancreatic diversion needs consensus. Obes Surg 2003;13:378-382.

87 Sardo P, Walker J: Bariatric surgery: impact on medication management. Hosp Pharm 2008;43:113-120. 
Busetto et al.: Practical Recommendations of the Obesity Management Task Force of the European Association for the Study of Obesity for the Post-Bariatric Surgery Medical Management

88 Marchi J, Berg M, Dencker A, Olander EK, Begley C: Risks associated with obesity in pregnancy, for the mother and baby: a systematic review of reviews. Obes Rev 2015;16:621-638.

89 Metsala J, Stach-Lempinen B, Gissler M, Eriksson JG, Koivusalo S: Risk of pregnancy complications in relation to maternal prepregnancy body mass index: population-based study from Finland 2006-10. Paediatr Perinat Epidemiol 2016;30:28-37.

90 Talmor A, Dunphy B: Female obesity and infertility. Best Pract Res Clin Obstet Gynaecol 2015;29:498-506.

91 Royal College of Obstetricians and Gynaecologists (RCOG): Bariatric Surgery in Improving Reproductive Health, The Role of (Scientific Impact Paper No. 17). 2015. www.rcog.org.uk/en/guidelines-research-services/ guidelines/sip17/ (last accessed November 22, 2017).

92 Rochester D, Jain A, Polotsky AJ, Polotsky H, Gibbs K, Isaac B, Zeitlian G, Hickmon C, Feng S, Santoro N: Partial recovery of luteal function after bariatric surgery in obese women. Fertil Steril 2009;92:1410-1415.

93 Legro RS, Dodson WC, Gnatuk CL, Estes SJ, Kunselman AR, Meadows JW, Kesner JS, Krieg EF Jr, Rogers AM, Haluck RS, Cooney RN: Effects of gastric bypass surgery on female reproductive function. J Clin Endocrinol Metab 2012;97:4540-4548.

94 Jamal M, Gunay Y, Capper A, Eid A, Heitshusen D, Samuel I: Roux-en-Y gastric bypass ameliorates polycystic ovary syndrome and dramatically improves conception rates: a 9-year analysis. Surg Obes Relat Dis 2012;8: 440-444.

95 Teitelman M, Grotegut CA, Williams NN, Lewis JD: The impact of bariatric surgery on menstrual patterns. Obes Surg 2006;16:1457-1463.

96 Musella M, Milone M, Bellini M, Sosa Fernandez LM, Leongito M, Milone F: Effect of bariatric surgery on obesity-related infertility. Surg Obes Relat Dis 2012;8:445-449.

97 Maggard MA, Yermilov I, Li Z, Maglione M, Newberry S, Suttorp M, Hilton L, Santry HP, Morton JM, Livingston EH, Shekelle PG: Pregnancy and fertility following bariatric surgery: a systematic review. JAMA 2008;300: 2286-2296.

98 Guelinckx I, Devlieger R, Vansant G: Reproductive outcome after bariatric surgery: a critical review. Hum Reprod Update 2009;15:189-201.

99 Parent B, Martopullo I, Weiss NS, Khandelwal S, Fay EE, Rowhani-Rahbar A: Bariatric surgery in women of childbearing age, timing between an operation and birth, and associated perinatal complications. JAMA Surg 2017;152:1-8.

100 Gonzalez I, Rubio MA, Cordido F, Breton I, Morales MJ, Vilarrasa N, Monereo S, Lecube A, Caixas A, Vinagre I, Goday A, Garcia-Luna PP: Maternal and perinatal outcomes after bariatric surgery: a Spanish multicenter study. Obes Surg 2015;25:436-442.

101 Heber D, Greenway FL, Kaplan LM, Livingston E, Salvador J, Still C. Endocrine and nutritional management of the post-bariatric surgery patient: an Endocrine Society Clinical Practice Guideline. J Clin Endocrinol Metab 2010;95:4823-4843.

102 The American Congress of Obstetricians and Gynecologists (ACOG): ACOG practice bulletin no. 105: bariatric surgery and pregnancy. Obstet Gynecol 2009;113:1405-1413.

103 Willis K, Lieberman N, Sheiner E: Pregnancy and neonatal outcome after bariatric surgery. Best Pract Res Clin Obstet Gynaecol 2015;29:133-144.

104 Kominiarek MA: Preparing for and managing a pregnancy after bariatric surgery. Semin Perinatol 2011;35: 356-361.

105 Willis K, Sheiner E: Bariatric surgery and pregnancy: the magical solution? J Perinat Med 2013;41:133-140.

106 Boots C, Stephenson MD: Does obesity increase the risk of miscarriage in spontaneous conception: a systematic review. Semin Reprod Med 2011;29:507-513.

107 Whyte M, Pring C, Cooke D, Hart K, McGowan BM, Subramanian D, Shave J: Pregnancy after diabetes obesity surgery (PADOS): incidence and outcomes. Pregnancy Hypertens 2014;4:239.

108 Alatishe A, Ammori BJ, New JP, Syed AA: Bariatric surgery in women of childbearing age. QJM 2013;106:717720.

109 Kjaer MM, Lauenborg J, Breum BM, Nilas L: The risk of adverse pregnancy outcome after bariatric surgery: a nationwide register-based matched cohort study. Am J Obstet Gynecol 2013;208:464.e1-5.

110 Roos N, Neovius M, Cnattingius S, Trolle Lagerros Y, Saaf M, Granath F, Stephansson O: Perinatal outcomes after bariatric surgery: nationwide population based matched cohort study. BMJ 2013;347:f6460.

111 Johansson K, Cnattingius S, Naslund I, Roos N, Trolle Lagerros Y, Granath F, Stephansson O, Neovius M: Outcomes of pregnancy after bariatric surgery. N Engl J Med 2015;372:814-824.

112 Lesko J, Peaceman A: Pregnancy outcomes in women after bariatric surgery compared with obese and morbidly obese controls. Obstet Gynecol 2012;119:547-554.

113 Patel JA, Patel NA, Thomas RL, Nelms JK, Colella JJ: Pregnancy outcomes after laparoscopic Roux-en-Y gastric bypass. Surg Obes Relat Dis 2008;4:39-45.

114 Belogolovkin V, Salihu HM, Weldeselasse H, Biroscak BJ, August EM, Mbah AK, Alio AP: Impact of prior bariatric surgery on maternal and fetal outcomes among obese and non-obese mothers. Arch Gynecol Obstet 2012;285: 1211-1218.

115 Chevrot A, Kayem G, Coupaye M, Lesage N, Msika S, Mandelbrot L: Impact of bariatric surgery on fetal growth restriction: experience of a perinatal and bariatric surgery center. Am J Obstet Gynecol 2016;214:655.e1-7. 
Busetto et al.: Practical Recommendations of the Obesity Management Task Force of the European Association for the Study of Obesity for the Post-Bariatric Surgery Medical Management

116 Facchiano E, Iannelli A, Santulli P, Mandelbrot L, Msika S: Pregnancy after laparoscopic bariatric surgery: comparative study of adjustable gastric banding and Roux-en-Y gastric bypass. Surg Obes Relat Dis 2012;8: 429-433.

117 Mead NC, Sakkatos P, Sakellaropoulos GC, Adonakis GL, Alexandrides TK, Kalfarentzos F: Pregnancy outcomes and nutritional indices after 3 types of bariatric surgery performed at a single institution. Surg Obes Relat Dis 2014;10:1166-1173.

118 Han SM, Kim WW, Moon R, Rosenthal RJ: Pregnancy outcomes after laparoscopic sleeve gastrectomy in morbidly obese Korean patients. Obes Surg 2013;23:756-759.

119 Gehrer S, Kern B, Peters T, Christoffel-Courtin C, Peterli R: Fewer nutrient deficiencies after laparoscopic sleeve gastrectomy (LSG) than after laparoscopic Roux-Y-gastric bypass (LRYGB)-a prospective study. Obes Surg 2010;20:447-453.

120 Ducarme G, Chesnoy V, Lemarie P, Koumare S, Krawczykowski D: Pregnancy outcomes after laparoscopic sleeve gastrectomy among obese patients. Int J Gynaecol Obstet 2015;130:127-131.

121 O’Keane M Pinkney J, Aasheim E, Barth B, Batterham R, Welbourn R: BOMSS Guidelines on Peri-Operative and Postoperative Biochemical Monitoring and Micronutrient Replacement for Patients Undergoing Bariatric Surgery. 2014. www.bomss.org.uk/wp-content/uploads/2014/09/BOMSS-guidelines-Final-version1Oct14.pdf (last accessed November 22, 2017).

122 Roehrig HR, Xanthakos SA, Sweeney J, Zeller MH, Inge TH: Pregnancy after gastric bypass surgery in adolescents. Obes Surg 2007;17:873-877.

123 Graham Y, Wilkes S, Mansour D, Small PK: Contraceptive needs of women following bariatric surgery. J Fam Plann Reprod Health Care 2014;40:241-244.

124 Victor A, Odlind V, Kral JG: Oral contraceptive absorption and sex hormone binding globulins in obese women: effects of jejunoileal bypass. Gastroenterol Clin North Am 1987;16:483-491.

125 Curtis KM, Tepper NK, Jatlaoui TC, Berry-Bibee E, Horton LG, Zapata LB, Simmons KB, Pagano JP, Jamieson DJ, Whiteman MK: U.S. medical eligibility criteria for contraceptive use, 2016. MMWR Recomm Rep 2016;65: 1-103.

126 Faculty of Sexual and Reproductive Health (FSRH): UK Medical Eligibility Criteria for Contraceptive Use (UKMEC 2016). London, FSRH; 2017. www.fsrh.org/documents/ukmec-2016/final-book-july-2017.pdf (last accessed November 22, 2017).

127 Ciangura C, Corigliano N, Basdevant A, Mouly S, Decleves X, Touraine P, Lloret-Linares C: Etonorgestrel concentrations in morbidly obese women following Roux-en-Y gastric bypass surgery: three case reports. Contraception 2011;84:649-651.

128 Hillman JB, Miller RJ, Inge TH: Menstrual concerns and intrauterine contraception among adolescent bariatric surgery patients. J Womens Health 2011;20:533-538.

129 Poitou Bernert C, Ciangura C, Coupaye M, Czernichow S, Bouillot JL, Basdevant A: Nutritional deficiency after gastric bypass: diagnosis, prevention and treatment. Diabetes Metab 2007;33:13-24.

130 Smets KJ, Barlow T, Vanhaesebrouck P: Maternal vitamin A deficiency and neonatal microphthalmia: complications of biliopancreatic diversion? Eur J Pediatr 2006;165:502-504.

131 Weissman A, Hagay Z, Schachter M, Dreazen E: Severe maternal and fetal electrolyte imbalance in pregnancy after gastric surgery for morbid obesity. A case report. J Reprod Med 1995;40:813-816.

132 Adam S, Ammori B, Soran H, Syed AA: Pregnancy after bariatric surgery: screening for gestational diabetes. BMJ 2017;356:j533.

133 Caranta DG, Lee AM, Pennington D, Zelig CM: Complications from Roux-en-Y gastric bypass mistaken for medical complications in gravid patients. Obstet Gynecol 2014;124(suppl 1):464-466.

134 Andreasen LA, Nilas L, Kjaer MM: Operative complications during pregnancy after gastric bypass-a registerbased cohort study. Obes Surg 2014;24:1634-1638.

135 Jefferys AE, Siassakos D, Draycott T, Akande VA, Fox R: Deflation of gastric band balloon in pregnancy for improving outcomes. Cochrane Database Syst Rev 2013;1:Cd010048.

136 Pilone V, Hasani A, Di Micco R, Vitiello A, Monda A, Izzo G, Iacobelli L, Villamaina E, Forestieri P: Pregnancy after laparoscopic gastric banding: maternal and neonatal outcomes. Int J Surg 2014;12(suppl 1):S136-139.

137 Celiker MY, Chawla A: Congenital B12 deficiency following maternal gastric bypass. J Perinatol 2009;29:640642.

138 Kinzl JF, Maier C, Bosch A: Morbidly obese patients: psychopathology and eating disorders. Results of a preoperative evaluation. Neuropsychiatry 2012;26:159-165.

139 Heneghan HM, Heinberg L, Windover A, Rogula T, Schauer PR: Weighing the evidence for an association between obesity and suicide risk. Surg Obes Relat Dis 2012;8:98-107.

140 Tindle HA, Omalu B, Courcoulas A, Marcus M, Hammers J, Kuller LH: Risk of suicide after long-term follow-up from bariatric surgery. Am J Med 2010;123:1036-1042.

141 Chen EY, Fettich KC, McCloskey MS: Correlates of suicidal ideation and/or behavior in bariatric-surgeryseeking individuals with severe obesity. Crisis 2012;33:137-143.

142 Omalu BI, Cho P, Shakir AM, Agumadu UH, Rozin L, Kuller LH, Wecht CH: Suicides following bariatric surgery for the treatment of obesity. Surg Obes Relat Dis 2005;1:447-449.

143 Mitchell JE, Crosby R, de Zwaan M, Engel S, Roerig J, Steffen K, Gordon KH, Karr T, Lavender J, Wonderlich S: Possible risk factors for increased suicide following bariatric surgery. Obesity (Silver Spring) 2013;21:665672. 
Busetto et al.: Practical Recommendations of the Obesity Management Task Force of the European Association for the Study of Obesity for the Post-Bariatric Surgery Medical Management

144 Wee CC, Mukamal KJ, Huskey KW, Davis RB, Colten ME, Bolcic-Jankovic D, Apovian CM, Jones DB, Blackburn GL: High-risk alcohol use after weight loss surgery. Surg Obes Relat Dis 2014;10:508-513.

145 King WC, Chen JY, Mitchell JE, Kalarchian MA, Steffen KJ, Engel SG, Courcoulas AP, Pories WJ, Yanovski SZ: Prevalence of alcohol use disorders before and after bariatric surgery. JAMA 2012;307:2516-2525.

146 Saunders R: Post-surgery group therapy for gastric bypass patients. Obes Surg 2004;14:1128-1131.

147 Segal A, Kinoshita Kussunoki D, Larino MA: Post-surgical refusal to eat: anorexia nervosa, bulimia nervosa or a new eating disorder? A case series. Obes Surg 2004;14:353-360.

148 Kushner RF, Sorensen KW: Prevention of weight regain following bariatric surgery. Curr Obes Rep 2015;4: 198-206.

149 Abu Dayyeh BK, Lautz DB, Thompson CC: Gastrojejunal stoma diameter predicts weight regain after Roux-enY gastric bypass. Clin Gastroenterol Hepatol 2011;9:228-233.

150 ASMBS Professional Resource Center: https://asmbs.org/resources/ (last accessed November 22, 2017).

151 Fried M, Yumuk V, Oppert JM, Scopinaro N, Torres AJ, Weiner R, Yashkov Y, Frühbeck G: Interdisciplinary European guidelines on metabolic and bariatric surgery. Obes Facts 2013;6:449-468.

152 Uerlich MF, Yumuk V, Finer N, Basdevant A, Visscher TL: Obesity management in Europe: current status and objectives for the future. Obes Facts 2016;9:273-283.

153 Hainer V, Tsigos C, Toplak H, Micic D. Comment on the paper by Uerlich et al: Obesity management in Europe: current status and objectives for the future. Obes Facts 2016;9:273-283. Obes Facts 2016;9:392-396.

154 Faria SL: Dietary protein intake and bariatric surgery. Obes Surg 2011;21:1798-1805.

155 Kulick D, Hark L, Deen D: The bariatric surgery patient: a growing role for registered dietitians. J Am Diet Assoc 2010;110:593-599.

156 Ziegler O, Sirveaux MA, Brunaud L, , Reibel N, Quilliot D: Medical follow up after bariatric surgery: nutritional and drug issues. General recommendations for the prevention and treatment of nutritional deficiencies. Diabetes Metab 2009;35:544-557.

157 Tsigos C, Hainer V, Basdevant A, Finer N, Mathus-Vliegen E, Micic D, Maislos M, Roman G, Schutz Y, Toplak H, Yumuk V, Zahorska-Markiewicz B: Criteria for EASO-collaborating centres for obesity management. Obesity Management Task Force of the European Association for the Study of Obesity. Obes Facts 2011;4:329-333.

158 Toplak H, Woodward E, Yumuk V, Oppert JM, Halford JC, Frühbeck G: 2014 EASO position statement on the use of anti-obesity drugs. Obes Facts. 2015;8:166-174.

159 Stanford FC, Alfaris N, Gomez G, Ricks ET, Shukla AP, Corey KE, Pratt JS, Pomp A, Rubino F, Aronne LJ: The utility of weight loss medications after bariatric surgery for weight regain or inadequate weight loss: a multicenter study. Surg Obes Relat Dis 2017;13:491-500.

160 Schwartz J, Chaudhry UI, Suzo A, Durkin N, Wehr AM, Foreman KS, Tychonievich K, Mikami DJ, Needleman BJ, Noria SF: Pharmacotherapy in conjunction with a diet and exercise program for the treatment of weight recidivism or weight loss plateau post-bariatric surgery: a retrospective review. Obes Surg 2016;26:452-458.

161 Pajecki D, Halpern A, Cercato C, Mancini M, de Cleva R, Santo MA: Short-term use of liraglutide in the management of patients with weight regain after bariatric surgery. Rev Col Bras Cir 2013;40:191-195. 